\title{
Kinematic Fields Measurement during Orthogonal Cutting Using Digital Images Correlation: A Review
}

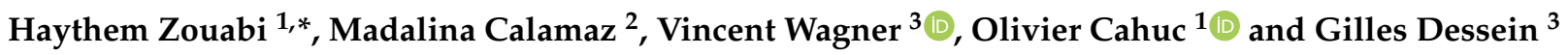 \\ 1 Arts et Metiers Institute of Technology, University of Bordeaux, CNRS, Bordeaux INP, INRAE, I2M Bordeaux, \\ F-33400 Talence, France; olivier.cahuc@u-bordeaux.fr \\ 2 Arts et Metiers Institute of Technology, University of Bordeaux, CNRS, Bordeaux INP, INRAE, HESAM \\ Université, I2M Bordeaux, F-33400 Talence, France; madalina.CALAMAZ@ENSAM.Eu \\ 3 Laboratoire Génie de Production, ENIT-INPT, Université de Toulouse, 65440 Tarbes, France; \\ vincent.wagner@enit.fr (V.W.); gilles.dessein@enit.fr (G.D.) \\ * Correspondence: haythem.zouabi@u-bordeaux.fr
}

Citation: Zouabi, H.; Calamaz, M.; Wagner, V.; Cahuc, O.; Dessein, G. Kinematic Fields Measurement during Orthogonal Cutting Using Digital Images Correlation: A Review. J. Manuf. Mater. Process. 2021, 5, 7 . https://doi.org/10.3390/jmmp5010007

Received: 3 December 2020

Accepted: 1 January 2021

Published: 9 January 2021

Publisher's Note: MDPI stays neutral with regard to jurisdictional claims in published maps and institutional affiliations.

Copyright: $\odot 2021$ by the authors. Licensee MDPI, Basel, Switzerland. This article is an open access article distributed under the terms and conditions of the Creative Commons Attribution (CC BY) license (https: / / creativecommons.org / licenses/by/4.0/).
Abstract: Understanding the mechanism of chip formation during orthogonal cutting requires a local measurement of the displacement and strain fields in the cutting zone. These measurements can then be used in order to enhance/validate numerical simulation of metal cutting or calibrate material behavior laws for a better prediction of the thermomechanical loads inside the cutting zone. Particle tracking to identify the strain localization that is exhibited in the Adiabatic Shear Band (ASB) is a challenging task. These local measurements can be determined by images post-processing while using the Digital Image Correlation (DIC) technique or analytical models using streamline models or by micro grid analysis. Recently, the use of the DIC technique is widely increased. Texture quality has been shown to be an important factor. Various techniques of surface preparation are then discussed and classified in terms of the created pattern size. Tools for texture analysis are presented. The technique suitability for the kinematic fields measurement while using the DIC technique during machining is discussed. Various optical systems of the literature employed in the context of kinematic fields measurement during machining are discussed in this paper. The recent advances on the design of optical systems are given. Finally, the results of kinematic fields measurement during machining metallic alloys are analyzed.

Keywords: orthogonal cutting; surface preparation; texture analysis; high-speed camera; optical devices; kinematic fields measurement

\section{Introduction}

Numerical simulations of metal cutting enable the prediction of the thermomechanical loads that helps to optimize the cutting process. Therefore, it helps to reduce the number and cost of experiments. During orthogonal cutting, the material undergoes high plastic deformation and temperature increase in the primary (PSZ), the secondary (SSZ), and the tertiary shear zones (TSZ). The PSZ is subjected to high deformation with a strain rate that generally exceeds $10^{3} \mathrm{~s}^{-1}$ [1-3]. Finite element modeling of metal cutting requires both suitable material behavior law and friction law for accurate prediction. The Johnson Cook (JC) model [4] was widely used for numerical simulation of metal cutting. This model accounts for the material strain hardening, strain rate hardening, and thermal softening at high strain rates. However, for material undergone chip segmentation at low cutting speeds, this model shows its weakness of prediction of the thermomechnaical load. The model gives continuous chip, instead of a segmented one. Several works have been carried out in order to modify the JC model to enable good prediction of the thermomechanical load during metal cutting. With an extension of the JC model, Calamaz et al. [5] proposed a model that accounts for the material strain softening that is dependent on the equivalent strain and temperature. The model shows the good prediction of segmented chip for a wide cutting 
speed range. A good prediction of the cutting forces has been found at low cutting speeds ( $<67 \mathrm{~m} / \mathrm{min}$ ) on Ti-6Al-4V alloy. This model was later used by Sima [6] for numerical simulation and experimental validation when cutting Ti-6Al-4V alloy. Numerous works has been adressed to modify the JC model. A good prediction of the thermo-mechanical load was shown to be also dependent from the implemented friction law [7-9].

Currently, numerical simulation results are compared with the experimental ones at the macroscopic level [5,6,10-12] through (i) force components measurements, (ii) postmortem analysis giving the chip morphologies, its geometrical characteristics [13], and with an SEM ("Scanning Electron Microscopy") analysis [14-18], (iii) in-situ measurement of the tool-chip contact length $[7,19,20]$, and (iv) temperature measurement at the tool tip using inverse methods [9,21-23].

The displacement field measurement provide quantitative data that help to predict the strain, strain rates, stress, and surface integrity [24,25]. In addition, local data measurements enable enhancing and validating numerical models that could better describe the thermomechanical load at the local scale.

Three techniques were used for kinematic fields measurement during orthogonal cutting: (i) microgrid analysis, (ii) streamlines model, and (iii) the Digital Image Correlation (DIC) technique. The grid technique was first employed. This technique involves printing a well-defined grid squares on the surface of a workpiece. During the orthogonal cutting test, the grid is subjected to the same displacement as the workpiece material. Thus, by analyzing the distorsion of the deformed grid, the plastic strain field can be found.

In 1965, Bitans et al. [26] employed the grid technique while using a Quik-Stop Device (QSD) $[27,28]$ to study: (i) the relationship between the shear angle and the rake angle of the tool, (ii) qualitatively, the effect of the tool sharpness on the deformation state near the tool tip, and (iii) the measured cutting forces over the calculated forces by applying the theory of perfect plasticity. Later, in 1971, Childs et al. [29] employed the same technique in order to study the material flow during orthogonal cutting on mild steel. The surface of the workpiece was polished and a grid with squares of $25.4 \mu \mathrm{m}$ was printed. In 1982, Jeelani et al. [30,31] used an embossing method to produce microgrid on both annealed $18 \%$ Ni margaging steel and annealed brass. Grid squares of $12.7 \mu \mathrm{m}$ were obtained. Recently, Ghadbeigi et al. [32] used the Electron Beam Lithography to make an ultra-fine microgrid of gold on an AA5182 aluminium alloy. The grid square size was $10 \mu \mathrm{m}$ and the grid's line width was less than $1 \mu \mathrm{m}$. Orthogonal cutting tests were carried out with a cutting speed of $2.4 \mathrm{~m} / \mathrm{min}$ and a feed of $0.5 \mathrm{~mm}$. A QSD was used. After freezing the cutting process, the distorded ultra-fine microgrid was observed using a SEM. By analyzing the grid distorsions, the maximum plastic stain within the subsurface of the workpiece was found to reach 2.2. On the other hand, Pujana et al. [33] used a rotatory laser machine to produce a $65 \mu \mathrm{m}$ microgrid on a $42 \mathrm{CrMo} 4$ steel material.

The flow lines scratching technique was employed by [34] in 2008 to study the deformation fields during an Equal Channel Angular Extrusion (ECAE)of Al6061 aluminium alloy workpieces. Four flow lines were scratched on the cross-section while using a diamond stylus. After extrusion, the workpiece was photographed. Subsequently, the shape of the flow lines was analyzed using the "streamline models" to determine the deformation fields. Based on the work in [34], Bi and List [35,36] used the same technique to investigate the material flow during orthogonal cutting. This method can be applied only to a continuous chip formation [29]. The orthogonal cutting test was carried out on a mild steel AISI 1018 with a cutting speed of $1020 \mathrm{~m} / \mathrm{min}$ [36]. Using a mechanical scratching method, four flow lines were scratched parallel to the cutting direction. A high feed of $0.84 \mathrm{~mm}$ was used because of the high flow line spacing and in order to ensure a sufficient spatial resolution around the primary shear zone. The shape of the flow lines was analyzed while using the streamlines model to determine the deformations fields.

Microgrid analysis was found difficult to apply in the PSZ due to high distorsion [32], while the streamlines model has been shown to be limited to continuous chip formation $[29,35,36]$. However, the highly interest in increasing the accuracy of numerical simu- 
lations of machining has led researchers to develop experimental systems for in-process visualization of the material flow in the cutting zones.

Recently, optical imaging systems have been successfully implemented for in-situ measurement of the kinematic fields during machining. They offer real-time insight on the material flow through surface observation in the tool tip vicinity, within a sub-milimetric region of investigation (Figure 1) [37-47]. The DIC technique was used in order to identify high localized deformation band within the PSZ [41-44,46-48].

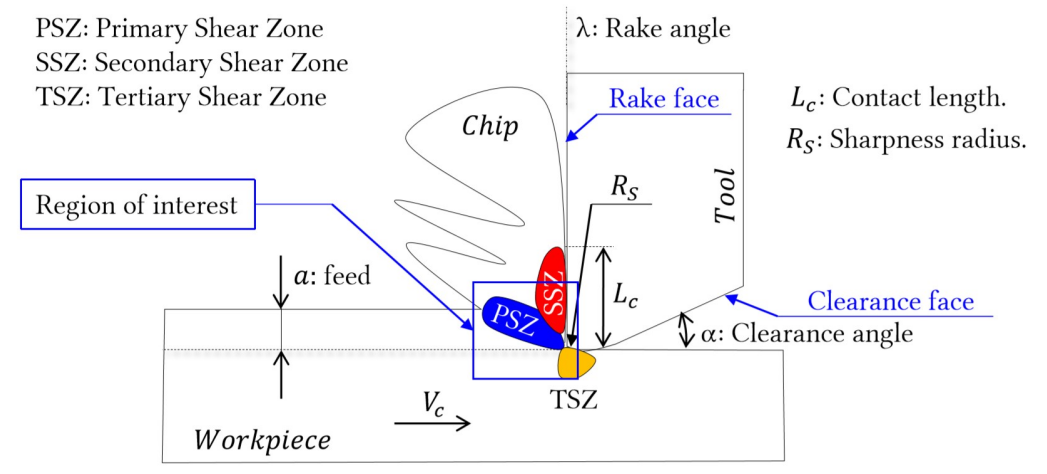

Figure 1. Cutting zones and the region of interest.

The DIC technique is used to measure the displacement and strain fields that are based on images post-processing. Two images, denoted by the reference and the deformed images, are required. A region of interest (ROI) is selected in the reference image and discretized into $\mathrm{N} \times \mathrm{N}$ square subsets or speckle patterns. Each speckle pattern must contain enough of an intensity gradient (or grey level intensity variation) to ensure a unique correspondance in the deformed image. During the matching procedure, each speckle pattern in the reference image is used to track its location in the deformed image.

During machining, images from the cutting zones are recorded while using a specific optical systems. The choice of the magnification lens is usually made with respect to the size of the region of investigation. The ROI does not exceed $1 \mathrm{~mm}^{2}$ when observing the PSZ and $2 \mathrm{~mm}^{2}$ when observing the subsurface of the workpiece [24,25]. For example, in the case of orthogonal cutting on Ti-6Al-4V, it was found that, in the range of cutting speeds between 3 and $30 \mathrm{~m} / \mathrm{min}$., the frame rate allowing for obtaining sufficient images of one segment chip formation is in the range of 6000 to $50,000 \mathrm{fps}[48,49]$. Therefore, the choice of the high-speed camera should be made, so that it allows capturing with frame rates ranging between 6000 and 50,000 textitfps. In this case, the inter-frame time ranges between $20 \mu \mathrm{s}$ and $100 \mu \mathrm{s}$. Otherwise, a dual-frame camera allows for considerably reducing the inter-frame time to $120 \mathrm{~ns}[24,38]$.

Image post-processing tools that are used for the displacement fields measurement during machining are divided into two main categories: (i) analytical methods, including both streamlines model [34-36] and micro grids analysis [32,33] and (ii) the numerical method using the DIC technique. Each methods requires a specific technique of surface preparation.

Because the ROI does not exceed $1 \mathrm{~mm}^{2}$, this disables any strain gauges to be mounted. In order to overcome this issue, the use of a non-contact technique for kinematic fields measurement has been employed. Recently, optical imaging systems has been successfully implemented for in-situ measurement of the kinematic fields during machining $[24,38,43,48,49]$. It offers real-time insight on the material flow thorugh surface observation. The application of the DIC technique on captured images leads to determining the kinematic fields. This article gives a review on kinematic fields measurement during orthogonal cutting while using the DIC technique. The experimental results in term of displacement, strain, and strain rate fields can then be used to enhance/validate numerical simulation or to calibrate material behavior laws.

Figure 2 shows the synoptic scheme of the article. First, the fundamentals of the DIC technique are given in Section 2. Section 3 gives details on techniques that are used 
for surface preparation of the workpiece for DIC post-processing. These techniques are discussed and classified in terms of the created pattern size. Tools for texture analysis are presented. Subsequently, Section 4 gives basics and analyzes high-speed camera fundamentals. The definition of each optical parameter is given and methods for identifying the appropriate optical parameters are presented. Section 5 gives details on the previously designed optical systems. Optical and mechanical parameters that are used for instrumented orthogonal cutting are summarized at the end of this section. Following this order and after instrumented orthogonal cutting tests, this paper ends with Section 6, giving the results of kinematic fields measurement during orthogonal cutting $[24,43,47,49]$ and discussing the application of the DIC technique.

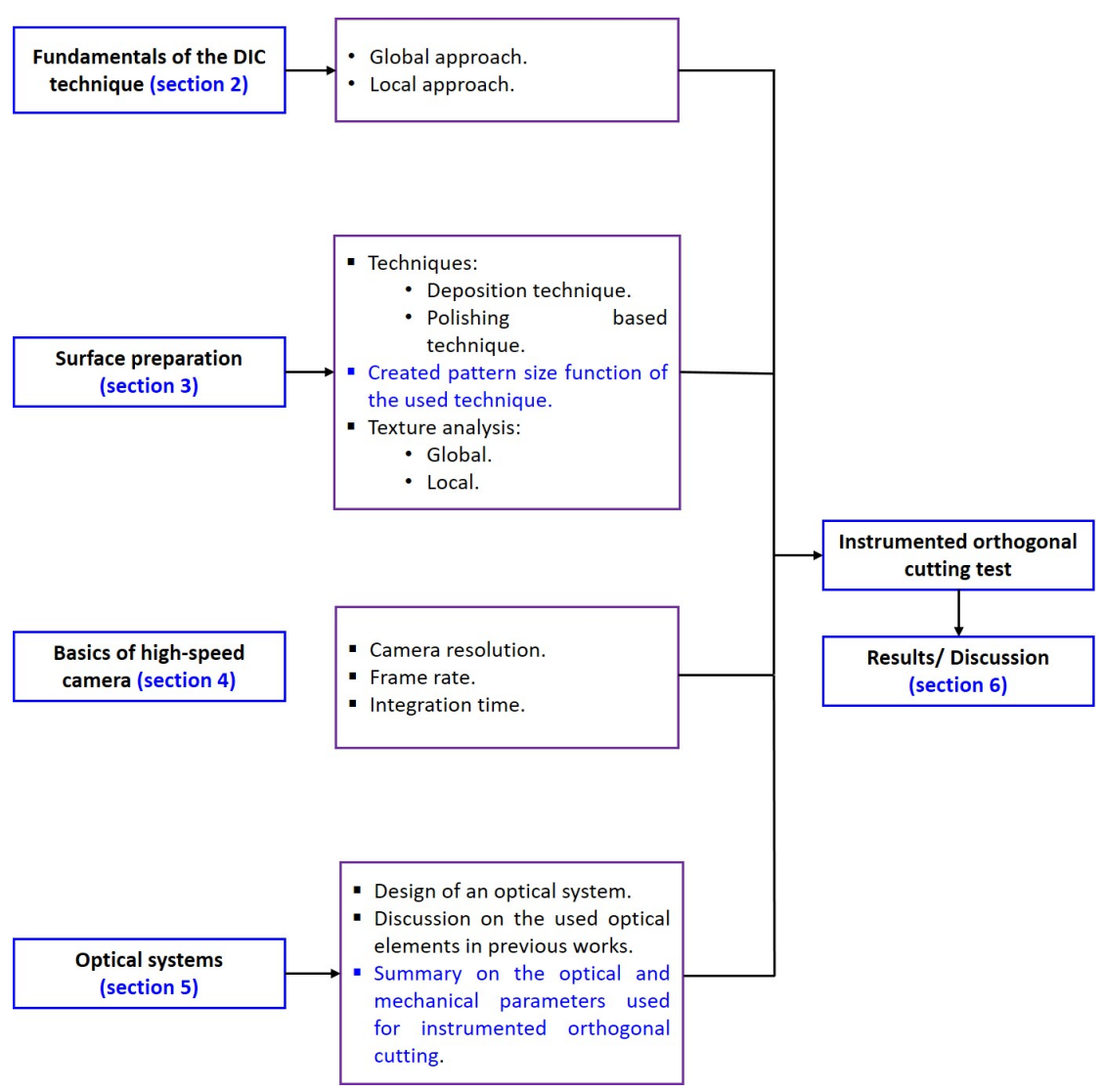

Figure 2. Synoptic scheme of the article.

\section{Fundamentals of the DIC Technique}

Recently, the use of the DIC technique is widely increased. It allows for measuring a full-field displacement with sub-pixel accuracy and estimating the full-field strain. In this section, the two approaches of the DIC technique are given and the main difference is highlighted.

\subsection{Global Approach}

In the global approach (or the so called finite element-based approach [50]), the ROI (Region of interest) is discretized into finite elements, denoted by $\Omega_{m}$ (Figure 3). As adjacent elements share two same nodes, this approach ensures continuity of the displacement. Assume that the ROI is discretized into M quadrilateral elements, which gives a total number of nodes, denoted by $\mathrm{N}$. The global approach aims to determine the nodal displacement components: for each node, the $\mathrm{x}$ - and $\mathrm{y}$-directional displacement denoted, respectively, by $u$ and $v$ are determined. Before that, the definition of the correlation criterion that aims to identify the degree of similarity between the speckle pattern in the reference image and the deformed image in terms of grey level is made. Subsequently, the pattern matching 
is made by either maximizing the Cross-Correlation Criterion $\left(C_{C C}\right)$ or minimizing the Sum of Squared Differences correlation criterion $\left(C_{S S D}\right)$ over the hole ROI, denoted by $\Omega$. For more details about the $C_{C C}$ and $C_{S S D}$ correlation criterion, the lecturer can refer to [51].

It was found that the simple $C_{S S D}$ criterion was widely used with the global approach, according to [50]. This criterion has shown to be sensitive to a scale in lighting. During machining, images recorded from one segment chip formation suffer from a loss of light due to out-of-plane motion. The last leads to difficulties in applying the DIC technique. On the other side, when studying the surface integrity [24], only two images are used: one before the cut and one after the cut. The subsurface of the workpiece is less subjected to an out-of-plane motion and almost constant lightening is ensured. Therefore, the application of the DIC technique with the global approach using the simple $C_{S S D}$ criterion is reasonable for studying the surface integrity. The simple $C_{S S D}$ criterion over the hole ROI is given by:

$$
C_{S S D, \Omega}\left(p_{\Omega}\right)=\sum_{m=1}^{M} C_{S S D, \Omega_{m}}=\sum_{m=1}^{M} \sum_{\Omega_{m}}\left[f(x, y)-g\left(x^{\prime}, y^{\prime}\right)\right]^{2}
$$

where $f(x, y)$ is the gray level of the pixel at the position $(x, y)$ located in an element $\Omega_{m}$ in the reference image, $g\left(x^{\prime}, y^{\prime}\right)$ is the gray level of the corresponding pixel in the deformed image situated at the position $\left(x^{\prime}, y^{\prime}\right)$ and $p_{\Omega}$ is the entire nodal displacement vector that is to be determined.

Because the global approach is based on the finite element description, the displacement components of each pixel located in the element $\Omega_{m}$ are given by:

$$
\left\{\begin{array}{l}
u_{\Omega_{m}}(x, y)=\sum_{i=1}^{k} N_{i}(\xi, \eta) u_{m i} \\
v_{\Omega_{m}}(x, y)=\sum_{i=1}^{k} N_{i}(\xi, \eta) v_{m i}
\end{array}\right.
$$

where $\xi \in[-1,1]$ and $\eta \in[-1,1]$ are the local coordinates of a pixel $(x, y)$ located in the element $\Omega_{m}, u_{m i}$ and $v_{m i}$ are the $x$ - and $y$-directional displacement, respectively, of the $i$-th node within the m-th element $\Omega_{m}, N_{i}$ refers to the shape function of the $i$-th node, and $k$ is the total number of nodes of the element $\Omega_{m}$.

Using the global approach, each speckle pattern is linked to its neighbors by nodes. Therefore, overlap between the speckle patterns is not possible and the measured displacement field is assumed to be a two-dimensional (2D) continium displacement field.

\subsection{Local Approach}

The local approach differs from the global one in the way that the pattern matching procedure is made (Figure 3). While using this approach, the pattern matching is made seperately for each speckle pattern.

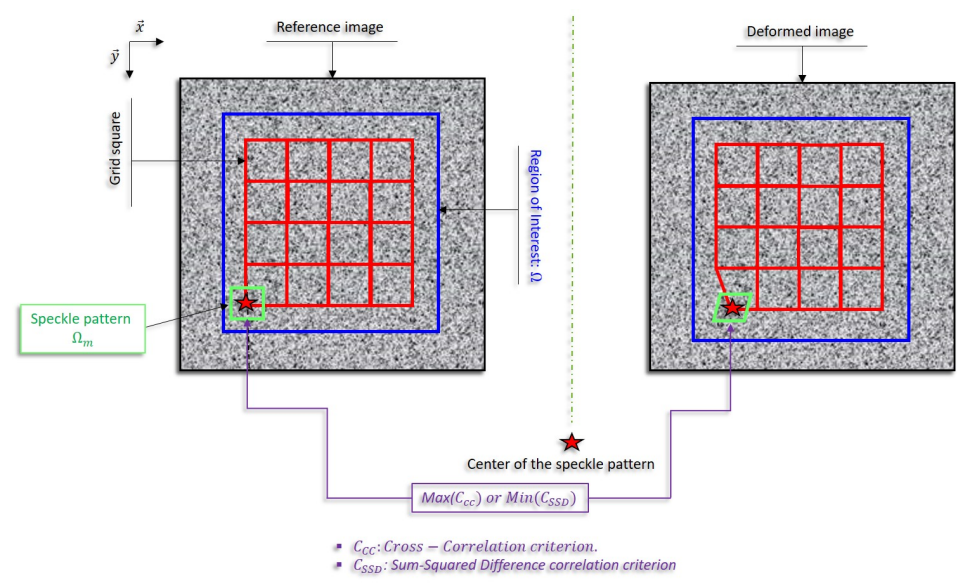

Figure 3. Schematic illustration of the principle of the Digital Image Correlation (DIC) with local approach. 
The correlation criterion is given by:

$$
C_{C C o r S S D, \Omega_{m}}=\sum_{\Omega_{m}} C_{C C o r S S D}
$$

where CC are the commonly used cross-correlation criteria, which are the simple CrossCorrelation (CC) or the Normalized Cross-Correlation (NCC) or the Zero-Normalized Cross-Correlation (ZNCC). SSD are the commonly used sum of squared differences criteria that are the simple Sum of Squared Differences (SSD) or the Normalized Sum of Squared Differences (NSSD) or the Zero-Normalized Sum of Squared Differences (ZNSSD) [51]. Two types of correlation criteria are utilized in order to evaluate the possible matches of the speckle pattern: cross correlation $(C C)$ and sum of squared differences $(S S D)$.

$C C$ is a formulation that is based on scalar product; when speckle patterns in the reference and in the deformed images are matching, the scalar product is at maximum. Therefore, this criterion has to be maximized.

$S S D$ is a formulation based on sum of squared differences; the minimum of that function corresponds to the minimum deviation of matching.

A normalized version of the previous criteria is used to overcome problems, like variations of lighting, in the compared images. Using Zero-Normalized version of CC and $S S D$ formulations allows for overcoming both variations of lighting and contrast in the compared images.

The commonly used CC criteria are linked to the commonly used SSD criteria, as described in [51]. For example, the ZNSSD correlation criterion can be determined from the ZNCC correlation criterion as $C_{Z N S S D}=2\left[1-C_{Z N C C}\right]$. Therefore, in order to evaluate the degree of similarity between the speckle pattern in the reference and the deformed images, the minimization of the correlation residue is made either by minimizing the commonly used sum of squared differences correlation criterion or maximizing the commonly used cross-correlation criterion.

Pan et al. [51] mentioned that both the simple CC and SSD correlation criterion are sensitive to all lighting fluctuations, while the NCC and NSSD correlation criteria are only insensitive to a linear scale in lighting and the ZNCC and ZNSSD correlation criteria are insensitive to both offset and linear scale in lighting.

The difference between the position of the center of the reference speckle pattern and the center of the deformed speckle pattern yields to determine the displacement vector of the node. Because the shape of the reference speckle pattern changes in the deformed image (Figure 4), the speckle pattern shape functions must be defined before the matching procedure [51,52]. Therefore, for each point $Q\left(x_{i}, y_{i}\right)$ in the reference speckle pattern, the cooresponding coordinates in the deformed speckle pattern are determined according to the defined speckle pattern shape functions and they can be given by:

$$
\left\{\begin{array}{l}
x_{i}^{\prime}=x_{i}+\xi\left(x_{i}, y_{i}\right) \\
y_{i}^{\prime}=y_{i}+\eta\left(x_{i}, y_{i}\right)
\end{array}\right.
$$

where $\xi\left(x_{i}, y_{i}\right)$ and $\eta\left(x_{i}, y_{i}\right)$ are, respectively, the $x$ - and $y$-directional shape functions. If the material undergones a rigid body motion, then zero-order shape functions can be used and they are given by [51]:

$$
\left\{\begin{array}{l}
\xi_{0}\left(x_{i}, y_{i}\right)=u \\
\eta_{0}\left(x_{i}, y_{i}\right)=v
\end{array}\right.
$$

where $u$ and $v$ are respectively the $x$ - and $y$-directional displacement components. 


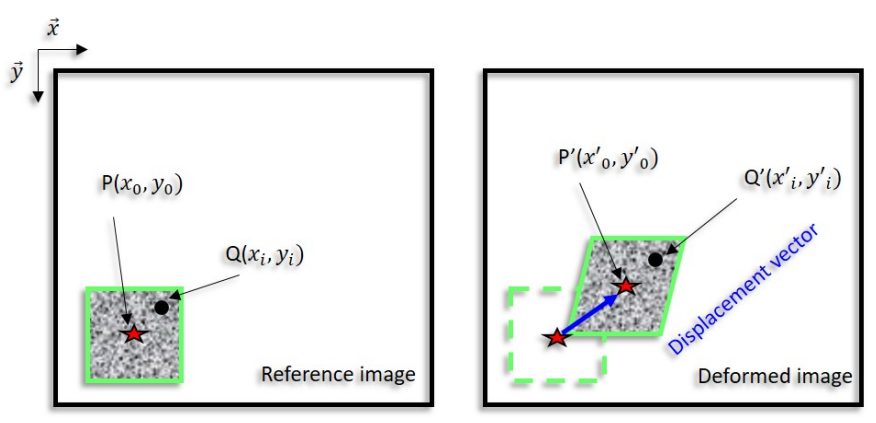

Figure 4. Illustration of the displacement vector of the speckle pattern center according to [51].

However, in orthogonal cutting, the material undergones translation, rotation, and shear. Thus, a minimum first-order shape function are required and they are defined by:

$$
\left\{\begin{array}{l}
\xi_{1}\left(x_{i}, y_{i}\right)=u+u_{x} \cdot \Delta x+u_{y} \cdot \Delta y \\
\eta_{1}\left(x_{i}, y_{i}\right)=v+v_{x} \cdot \Delta x+v_{y} \cdot \Delta y
\end{array}\right.
$$

where $u$ and $v$ are, respectively, the $x$ - and $y$-directional displacement components, $u_{x}$, $u_{y}, v_{x}$, and $v_{y}$ are the first order displacement gradient of the reference speckle pattern, $\Delta x=x_{i}-x_{0}$ and $\Delta y=y_{i}-y_{0}$. For the general expression of the speckle pattern shape function, the lecturer can refer to [52].

While using the local approach, each speckle pattern is analyzed independently. Overlap between the speckle patterns is possible. There is no issue when the speckle patterns overlap because each of the speckle patterns is analyzed independently in the local approach. In addition, this overlap implies an increase of the size of the speckle pattern, which helps to render it more discernable in the deformed image. The size of the speckle pattern is an important factor in determining the localized deformation band. The smaller the size of the speckle pattern, the higher the correlation procedure can identify a localized deformation band. However, reducing the size of the speckle pattern increases the difficulties to find its correspandence in the deformed image.

Moreover, most of the commercial and academic DIC softwares used the local approach. The Zero-Normalized Cross Correlation (ZNCC) and Zero-Normalized Sum of Squared Differences (ZNSSD) correlation criteria are integrated. These two correlation criteria are insensitive to a scale in lightening. Therefore, they are highly recommended for kinematic fields measurement during machining.

The main difference between the global and the local approach is in the way how the matching procedure is made. Minimization of the correlation residue is made over the whole region of interest when using the global approach while it is made separately for each speckle pattern when using the local approach. For the local approach, each speckle pattern is analyzed independently. The location of each speckle pattern does not depend on the location of its neighbours. However, in the global approach or the so called finite element approach, each speckle pattern is linked to its neighbours by the nodes. Then, the location of each speckle pattern depend on the location of its neighbours. Therefore, in the local approach, solution in terms of the nodal displacement vector does not depend on the nodal displacement vector of its neighbours, while it is not the case when using the global approach. Further, when using the global approach, the displacement of the region of interest is assumed to be a 2D continuum displacement.

\section{Surface Preparation of the Workpiece for DIC Post-Processing}

Surface preparation aims to create patterns that can be followed during the material flow. Various techniques of surface preparation were employed for in-situ investigation of the material flow during machining. This section aims to give an overview on the used techniques. Subsequently, these techniques are classified in terms of the created pattern size. In particular, criteria for texture assessment when using the deposition technique or the 
polishing based technique are presented and discussed. These two techniques of surface preparation are used for DIC post-processing. The results in terms of the created speckle pattern size are given and summarized in one table for all surface preparation techniques, including the grid technique and the flow lines scratching technique. These results help to compare and discuss the technique suitability for kinematic fields measurement during machining, in particular, during one segment chip formation. More attention is given to the criteria that help to identify the speckle pattern size, allowing for a proper application of the DIC technique. Figure 5 shows the techniques of surface preparation and criteria for texture assessment.

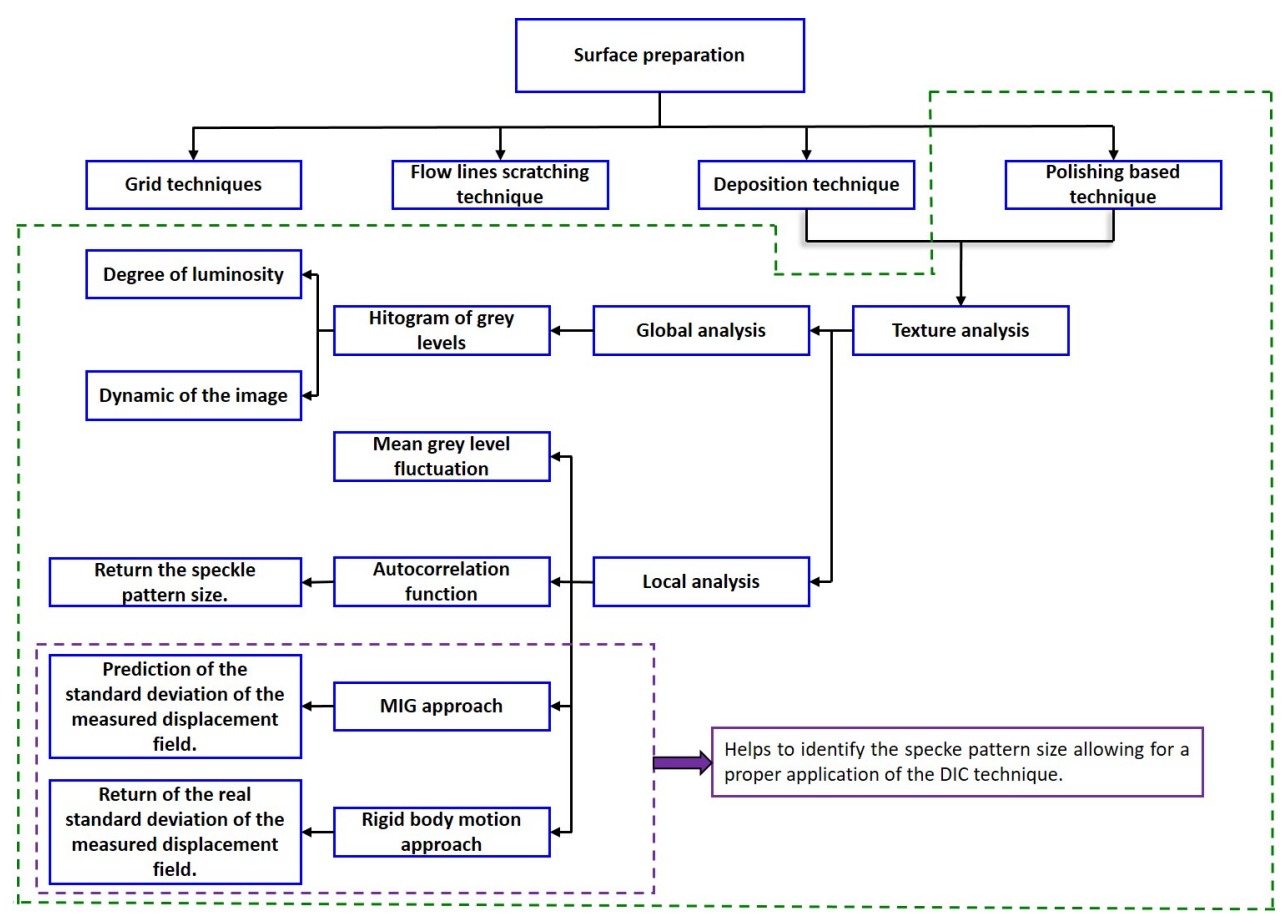

Figure 5. Surface preparation: techniques and texture assessment tools.

\subsection{Techniques}

\subsubsection{Deposition Technique}

This technique is widely known as a painting technique. An alternative was proposed in [53] in order to create a speckle resistant enough under high deformation and temperatures up to $1000{ }^{\circ} \mathrm{C}$. It was obtained by first polishing the surface of the workpiece to a roughness of $1 \mu \mathrm{m}$, followed by etching. Subsequently, a titanium dioxide powder that was diluted in ethanol was sprayed onto the polished surface. Using this method for kinematic fields measurement during orthogonal cutting, the obtained speckle has to withstand (i) large strain $(>150 \%)$ and (ii) a potentially high temperature $\left(1000{ }^{\circ} \mathrm{C}\right)$ generated during machining. By considering these constraints, the painting technique, considered to be the simplest technique, is excluded.

\subsection{2. "Polishing Based" Technique}

Polishing based technique refers to the techniques that first began by polishing, followed either by etching or sand blasting. Several authors used this technique [24,25,43,54-57].

Table 1 summarizes the techniques used for surface preparation for instrumented cutting tests with the associated results in terms of pattern size. The pattern size is important in the identification of the high localized deformation band. In this table, the pattern size refers to:

- the grid square size when using the grid technique (Gr) for the surface preparation;

- the lines spacing when using the flow lines scratching technique; and,

- the speckle pattern size when using the deposition or the "polishing based" technique. 
Table 1. Pattern size function of the material and the surface preparation technique.

\begin{tabular}{|c|c|c|c|}
\hline Reference/Year & Material & Techniques & Pattern Size $(\mu \mathrm{m})$ \\
\hline [26] 1965 & Wax & $\begin{array}{l}\text { Gr: scribing the lines } \\
\text { then casting the rubber mould. }\end{array}$ & 381 \\
\hline [29] 1971 & Brass & Gr: vickers microhardness machine. & 25.4 \\
\hline [30] 1982 & $\begin{array}{l}\text { Annealed } 18 \% \mathrm{Ni} \\
\text { maraging steel }\end{array}$ & Gr: microtome machine. & 12.7 \\
\hline [31] 1982 & Annealed red brass & Gr: microtome machine. & 12.7 \\
\hline [32] 2008 & AA5182 & Gr: EBL. & 10 \\
\hline [33] 2008 & $42 \mathrm{CrMo} 4$ & Gr: laser marking. & 65 \\
\hline ine [35] 2009 & NS ("Not specified") & Flow lines scratching. & NS \\
\hline [36] 2013 & AISI 1018 & Flow lines scratching. & $\approx 170$ \\
\hline ine [53] 2015 & Cast iron & Deposition & 225 \\
\hline [58] 2015 & CFRP & Deposition & 135 \\
\hline ine [59] 2005 & XC 1018 & Polishing + etching & NS \\
\hline [60] 2006 & Copper & Polishing & 16.5 \\
\hline [38] 2008 & AISI 1045 & Polishing & NS \\
\hline [39] 2009 & Al6061-T6 & Polishing & 41 \\
\hline [40] 2011 & $\begin{array}{l}42 \mathrm{CrMo} 4+ \\
42 \mathrm{CrMo} 4 \mathrm{E}\end{array}$ & Polishing & NS \\
\hline [42] 2012 & Ti-Mg & Polishing & NS \\
\hline [41] 2012 & Ti-6Al-4V & Polishing + etching & 19.2 \\
\hline [43] 2014 & Ti-6Al-4V & Polishing + etching & 16.5 \\
\hline [44] 2015 & Brass & Polishing & NS \\
\hline [61] 2015 & Copper & Polishing + etching & NS \\
\hline [54] 2017 & Al7075-T6 & Polishing + sandblasting & 35 \\
\hline [25] 2017 & AISI 52100 & Polishing + sandblasting & 17 \\
\hline [24] 2017 & AW7020-T6 & Polishing + sandblasting & 7.9 \\
\hline [55] 2018 & Al6061-T4 & Polishing + sandblasting & 10 \\
\hline [46] 2018 & Ti-6Al-4V & Polishing + etching & 18.12 \\
\hline [47] 2018 & Ti-6Al-4V/Ti54M & Polishing + etching & NS \\
\hline [48] 2018 & ECAE Ti & polishing & 75 \\
\hline \multirow[t]{2}{*}{ [57] 2019} & Nickel Aluminium & Polishing + sandblasting & NS \\
\hline & Bronze (NAB) & & \\
\hline
\end{tabular}

\subsubsection{Discussion/Comparison}

When using the grid technique analysis, a real-printed microgrid is made. The microgrid is subjected to the same displacement as the workpiece material. Subsequently, the measured displacement of each grid square nodes leads to determining the displacment field. Instead of using a real-printed microgrid, the DIC technique uses a virtual microgrid. Image post-processing while using the DIC technique leads to determining the displacement fields.

During machining, the printed microgrid on the surface of the workpiece is subjected to the same load as the workpiece. High deformation in very localized bands induces high distorsion of the printed microgrid. Therefore, the displacement field cannot be determined in this zone by applying the grid distorsion analysis. A high pattern size was obtained while using the deposition technique (225 $\mu \mathrm{m}$ in [53] and $135 \mu \mathrm{m}$ in [58]). Consequently, the spatial resolution of the displacement field measurement was low and it cannot be used to identify high localized deformations. On the other hand, the "polishing based" technique offered an acceptable pattern size that is sufficient enough to identify high localized deformations. A low pattern size $(7.9 \mu \mathrm{m})$ was obtained in [24] while using polishing + sandblasting on AW7020-T6. This value remains the lowest, even when compared with $[25,54,55,57]$ while using the same technique. In fact, the obtained pattern size is a function of the sandblasting pressure [24] and the dimeter of the abrasive partickle.

To conclude, it is found that the "polishing" based technique is the most suitable technique for kinematic fields measurement during machining. It offers an acceptable 
speckle pattern size, whose size is low enough to enable identifying high localized deformation band $[24,43,49]$. In addition, to guarantee a proper application of the DIC technique and to evaluate the texture quality, the following sub-section gives criteria/tools for texture analysis.

\subsection{Texture Analysis}

Texture analysis helps to determine the speckle pattern size allowing for the application of the DIC technique for the displacement field measurement. This section describes texture analysis that is based on images processing on surfaces that were prepared either by deposition techniques or "polishing based" techniques.

\subsubsection{Global Analysis}

Using a high-speed camera and for an 8-bit digitalization, each pixel in the image refered to a certain value in the [0.255] dynamic range. This value indicates the grey level of the pixel. Analyzing the grey levels histogram helps to identify:

- the degree of the image's luminosity; and,

- the grey level dynamic of the image $\left(\Delta N_{G}\right)$, where:

$$
\Delta N_{G}=N_{G \max }-N_{G \min }
$$

$N_{G \max }$ and $N_{G \min }$ are respectively the maximum and the minimum grey levels.

\subsubsection{Local Analysis}

Local analysis helps to evaluate wether the speckle pattern size is sufficient enough to allow a proper DIC application. Four criteria are used for this analysis: the mean gray level fluctuation, the autocorrelation function, the mean intensity gradient, and the rigid body motion approach. These criteria aim to determine the speckle pattern size, ensuring the application of the DIC technique with an acceptable standard deviation of the measured displacement, considered as an error.

\section{- Mean Gray Level Fluctuation}

Each of the speckle pattern in one image is characterized by its own gray level dynamic (Equation (7)). The latter quantity, averaged over all the speckle patterns of a given size, and normalized by the maximum gray level used in the image $\left(G_{\max }\right)$, gives the mean gray level fluctuation $m g f$ [62] expressed by:

$$
m g f=\frac{\sum_{i} \Delta N_{G, S P i}}{G_{\max }}
$$

where $\Delta N_{G, S P i}$ is the gray level dynamic of the speckle pattern number $i$ and $G_{\max }$ is the maximum gray level of the image.

According to $[63,64]$, the higher the mean gray level fluctuation $(m g f)$, the smaller the detection of displacement. However, increasing the $m g f$ means increasing the speckle pattern size, which affects the spatial resolution of the displacement fields measurement.

\section{- Autocorrelation function}

The autocorrelation function provides a quantification of the average size of local features that comprise the speckle pattern. It is a standard quantity [52] given by Equation (9). This function takes values between 0 and 1 .

$$
I(h)=\frac{\int_{\text {image }}(f(x)-F) *(f(x+h)-F) d x}{\int_{\text {image }}(f(x)-F)^{2} d x}
$$

where $f(x)$ is the gray level at position $x$ and $F$ is the average value of gray levels over the full image. $h$ is the norm of vector $h$ that is usually taken along the $x$-direction. For an 
isotropic pattern, the intensity of the autocorrelation function $(I(h))$ does not depend from the vector orientation. When $I(h)$ is equal to $0, h$ refers to the average size that comprises the speckle pattern.

Pottier [43] was the first to use this tool for a local texture analysis on Ti-6Al-4V microstructure in the context of kinematic fields measurement during machining.

- $\quad$ Mean Intensity Gradient (MIG)

Being developed by [65], the Mean Intensity Gradient (MIG) was defined in order to evaluate the quality of the entire speckle. It is given by the following equation:

$$
\delta_{f}=\sum_{i=1}^{W} \sum_{j=1}^{H} \frac{\left|\nabla f\left(x_{i j}\right)\right|}{W * H}
$$

where $(W, H)$ are the image width and height; $\left|\nabla f\left(x_{i j}\right)\right|=\sqrt{f_{x}\left(x_{i j}\right)^{2}+f_{y}\left(x_{i j}\right)^{2}}$ is the modulus of local gray level gradient vector and $\left(f_{x}\left(x_{i j}\right), f_{y}\left(x_{i j}\right)\right)$ are the gray level derivatives at pixel $x_{i j}$, respectively, along the $\mathrm{x}$ and $\mathrm{y}$ direction.

Pan et al. [65] demonstrated that the standard deviation of the measured displacement is function of the MIG $\left(\delta_{f}\right)$ :

$$
\sigma(U)=\frac{\sqrt{2} * \sigma}{m * \delta_{f}}
$$

where $\sigma(U)$ is the predicted standard deviation of the measured displacement, $\sigma$ is the standard deviation of the measurement noise that is determined by capturing two images before motion and $m$ is the speckle pattern size. For a given speckle pattern size $(m)$, images that are characterized by large MIG $\left(\delta_{f}\right)$ produce a small standard deviation.

- Rigid body motion approach

Based on [63] and defined by [43] in the context of kinematic fields measurement during machining, the rigid body motion approach was applied on a non-deformed zone in the image captured during the orthogonal cutting test. Over five successive images, this zone was assumed to move under the assumption of rigid body motion. Subsequently, the measured displacements (returned by the DIC technique) were substracted from the imposed displacement. Thus, the residual displacements that represent the displacement measurement uncertainties were obtained. Figure 6 provides the occurence of the residual displacements. It was fitted by a uniform distribution to determine the real standard deviation.

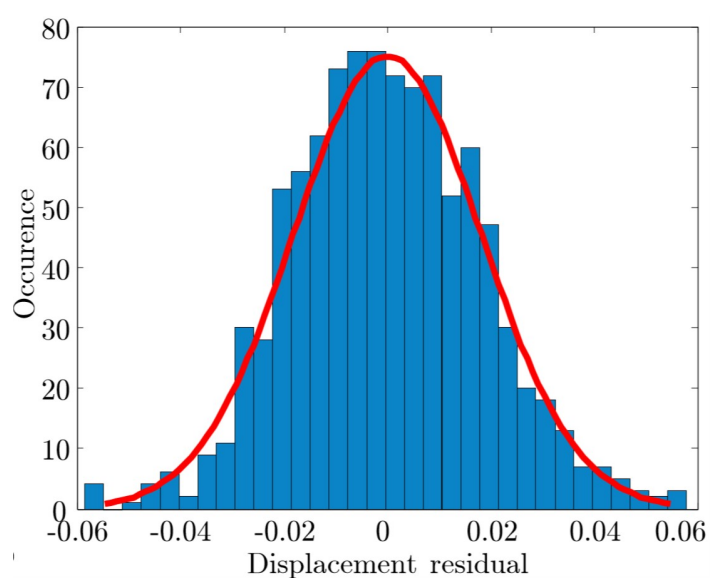

Figure 6. Occurence of residual displacements over 5 successives images [43]. 
The author found that. for a speckle pattern size of $16.5 \mu \mathrm{m} \times 16.5 \mu \mathrm{m}$, the standard deviation of the measured displacement is equal to 0.0181 pixels $\approx 0.031 \mu \mathrm{m}$. The latter matches well with the predicted standard deviation while using the MIG approach $(0.027 \mu \mathrm{m})$.

\section{Basics of High-Speed Camera}

This section gives the basics of high-speed camera and focus on the identification of the principle optical parameters: (i) the camera resolution, (ii) the frame rate, and (iii) the integration time.

\subsection{Camera Resolution}

The size of the region of investigation helps to identify the camera resolution. As mentioned above, in the context of kinematic fields measurement during machining, this zone does not exceed $1 \mathrm{~mm}^{2}$ when observing the PSZ and $2 \mathrm{~mm}^{2}$ when observing the subserface of the workpiece [24,25]. Each camera is characterized by its pitch: the metric size of one camera pixel. Hence, the camera resolution can be determined from:

$$
R=\frac{G * T}{\text { pitch }}
$$

where $R$ is the camera resolution, $G$ is the magnification, and $T$ is the size of the region of investigation.

\subsection{Frame Rate}

The frame rate refers to the number of images per second taken from the zone of investigation. The inverse of the frame rate gives the inter-frame time, which defines the temporal resolution of the measured kinematic fields.

The optimum frame rate can be determined from [66]:

$$
f_{a q}=\frac{N * V}{l}
$$

where $f_{a q}$ is the frame rate, $N$ is the number of images, $V$ is the speed of the object in motion, and $l$ is the length scale. In particular, when observing one segment chip formation during machining, $V$ refers to the cutting speed and $l$ refers to the segment width $[43,46]$. During orthogonal cutting on Ti-6Al-4V with a cutting speed of $6 \mathrm{~m} / \mathrm{min}$. and a feed of $0.25 \mathrm{~mm}$ (which is assumed to be equal to the segment width), Pottier et al. [43] obtained 45 images about one segment chip formation while using a frame rate of 18,000 fps.

\subsection{Integration Time}

The integration time refers to the time that is required to capture one frame. Mainly, it should be adjusted in order to obtain unblurred images that are required for a good image post-processing.

The optimum integration time [46] can be determined by minimizing the displacement (as given by the Equation (14)) of the observed zone during the capture time (the integration time):

$$
\operatorname{Dis}(\text { pixels })=\frac{V * t_{i}}{p}
$$

where Dis refers to the displacement expressed in pixels, $V$ is the speed, $t_{i}$ is the integration time, and $p$ is the pixel size.

The adjustment of the integration time depends from the light power. Two categories of light sources are available for high-speed imaging: (i) continuous light source or (ii) pulsed light source. Table 2 provides the types of light sources used in high-speed imaging. 
Table 2. Types of light sources used in high-speed imaging [67].

\begin{tabular}{ll}
\hline Source & Typical Duration (s) \\
\hline Sunlight & Continuous \\
T ungsten filament & Continuous \\
lamps & \\
Continuous arc source & Continuous \\
and gas discharge lamps & 0.5 to $5 \times 10^{-3}$ \\
Flash bulbs & $10^{-3}$ to $10^{-6}$ \\
Electronic flash & $10^{-6}$ to $10^{-7}$ \\
Argon bomb & $10^{-6}$ to $10^{-9}$ \\
Electricla spark & $10^{-7}$ to $10^{-9}$ \\
X-ray flash & $10^{-6}$ to $10^{-12}$ \\
Pulsed laser & $10^{-9}$ \\
Super radiant light source & Continuous \\
LED & or up to $5 \times 10^{-7}$ \\
\end{tabular}

Nowadays, LED sources are becoming more popular as a lighting source in high-speed imaging. Another light option is the pulsed laser. It offers the possibility to considerably reduce the inter-frame time when using a dual-frame camera (a minimum of $120 \mathrm{~ns}$ in $[24,38])$. LED and laser light sources both share the advantage that they are "cold light" and do not generate high temperatures, which could induce noise and affect the image quality [66]. Laser source has the unique advantage of unique wavelength illumination allowing to avoid diffraction and chromatic aberration.

Moreover, the choice of integration time also depends from two major parameters: (i) the light intensity and (ii) the camera sensitivity.

\section{Optical Systems}

The highly interest in understanding local phenomena during the chip formation has led many researchers to develop several optical devices. This section describes the major advances in the design of optical systems used in the context of kinematic fields measurement. Childs [29] was the first to develop an optical system for in-process visualization of the material flow during orthogonal cutting. Figure 7 shows this system. Two light beams enter a first beam splitter; then, the outgoing beams enter a collimator and then a second beam splitter to get coaxial (confocal) light. The duration of the light flash is limited to $2 \mu \mathrm{s}$ with a recharging time that is equal to $5 \mathrm{~s}$. The latter imposes the use of two lighting sources to take only a pair of images at a cutting speed equal to $0.254 \times 10^{-3} \mathrm{~m} / \mathrm{min}$.

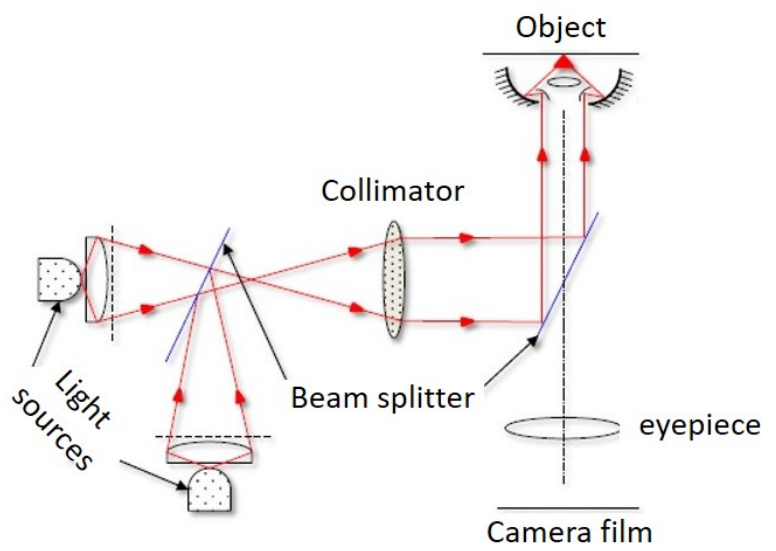

Figure 7. Scheme of the optical system used in [29] and described in [46]. 
By applying the grid analysis method, the author determines the kinematic fields. However, the temporal evolution of the kinematic fields cannot be obtained when only using two images.

In 2008, Hijazi [38] presented an optical system that is based on an X23 optical microscope equipped with four high-speed cameras (Figure 8a). It uses four laser sources with a beam combiner for coaxial illumination (Figure 8b). In order to limit the inter-frame time, the author uses a pulsed laser type illumination source with a pulse duration that ranges from 3 to $5 \mathrm{~ns}$. The time between two pulses must be greater than $500 \mathrm{~ns}$. The repetition frequency of a pair of pulses is very low (of the order of a few Hz, e.g., $15 \mathrm{~Hz}$ when using the Nd:YAG laser [24]). Thus, in order to allow for an ultra-high speed imaging and to obtain eight highly resolved images at a very high acquisition frequency (of the order of $\mathrm{MHz}), 4$ high-speed cameras are used in "double frame" mode. Thus, each high-speed camera records a pair of images with a very short inter-frame time (around $120 \mathrm{~ns}$ ).
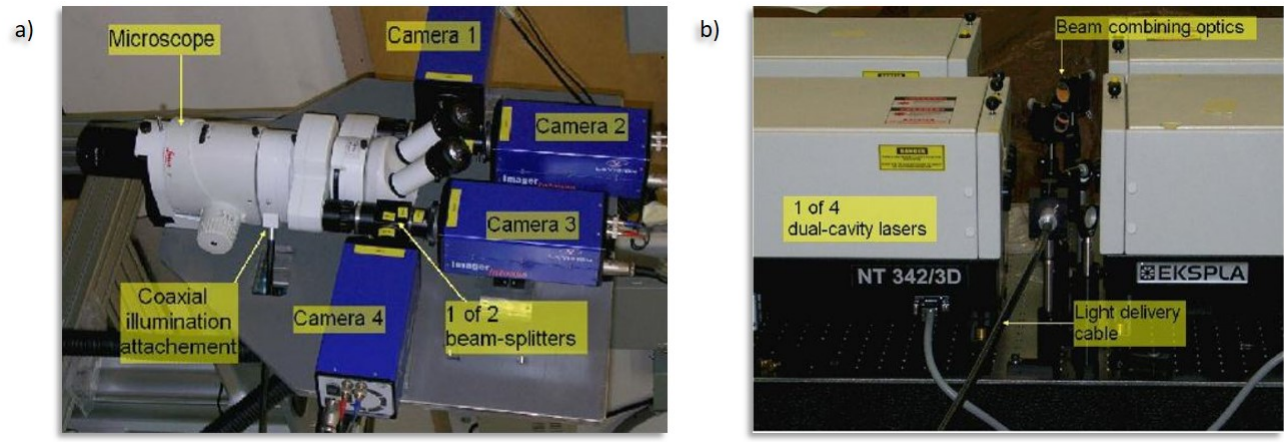

Figure 8. Utra-high speed imaging system developed by [38]: (a) four synchronized high-speed camera and (b) four combined pulsed laser sources.

Based on the work of [38] and by using the double-frame mode of the LaVision highspeed camera with a pulsed laser source (Figure 9), Baizeau [24] made it possible to capture a pair of images with an inter-frame time of $120 \mathrm{~ns}$. The used Nd:YAG dual pulsed laser produces pulses with a duration of 5 to $8 \mathrm{~ns}$. The first exposure time was reduced to $10 \mu \mathrm{s}$, while the second took $20 \mathrm{~ms}$. The optical system was equipped with an X10 magnification lens. In order to focus and distribute the laser light on the zone of investigation, an optical fiber with an expander was used. Orthogonal cutting test was carried out on AW7020-T6 with a cutting speed of $90 \mathrm{~m} / \mathrm{min}$. Although the double-frame mode made it possible to considerably reduce the inter-frame time in order to obtain a pair of highly resolved images, the use of the pulsed laser proves to be limiting in terms of the acquisition frequency of the camera, since the maximum repetition frequency is limited to $15 \mathrm{~Hz}$.

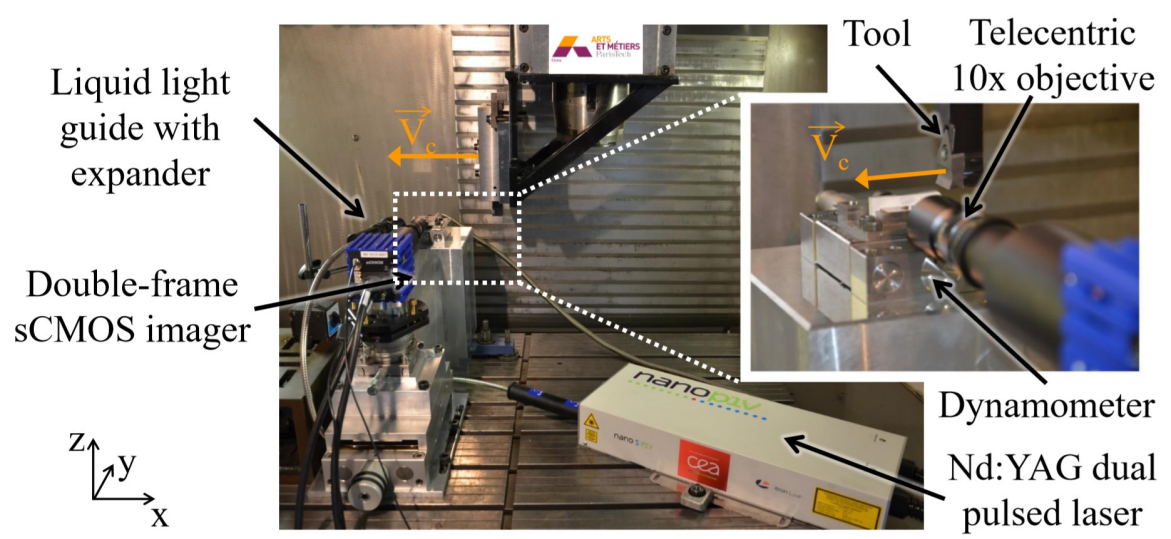

Figure 9. Optical system used in [24] to study the surface integrity. 
The MADMACS dual-spectrum optical system developed in [68] in the National Institute of Standards and Technology (NIST) laboratory enables coupled visible and thermal imaging. In order to ensure good lighting, two light sources (high-intensity visible light source) were used and guided by optical fibers. The first one is placed outside while the second one is integrated in it to obtain a coaxial illumination. The use of an R50/T50 beam splitter causes a loss in the coaxial light power. Only $25 \%$ of the initial light power is received by the high-speed camera sensors. High-speed and thermal cameras are coupled via two different optical channels (Figure 10). The radiation from the observed scene first goes through a protective sapphire window and then through a reflective X15 magnification lens (primary lens in Figure 10). At the intersection of the two channels, a cold mirror reflects waves from the visible range into the visible channel and then transmits waves from the infrared range into the infrared channel. The reflected visible waves goes through a tube lens that focuses the light towards the sensor of the high-speed camera. Ref. [68] shows that, while using this optical system, it is possible to capture images of $1 \mathrm{~mm}^{2}$ size with the different mechanical and optical parameters presented in Table 3.

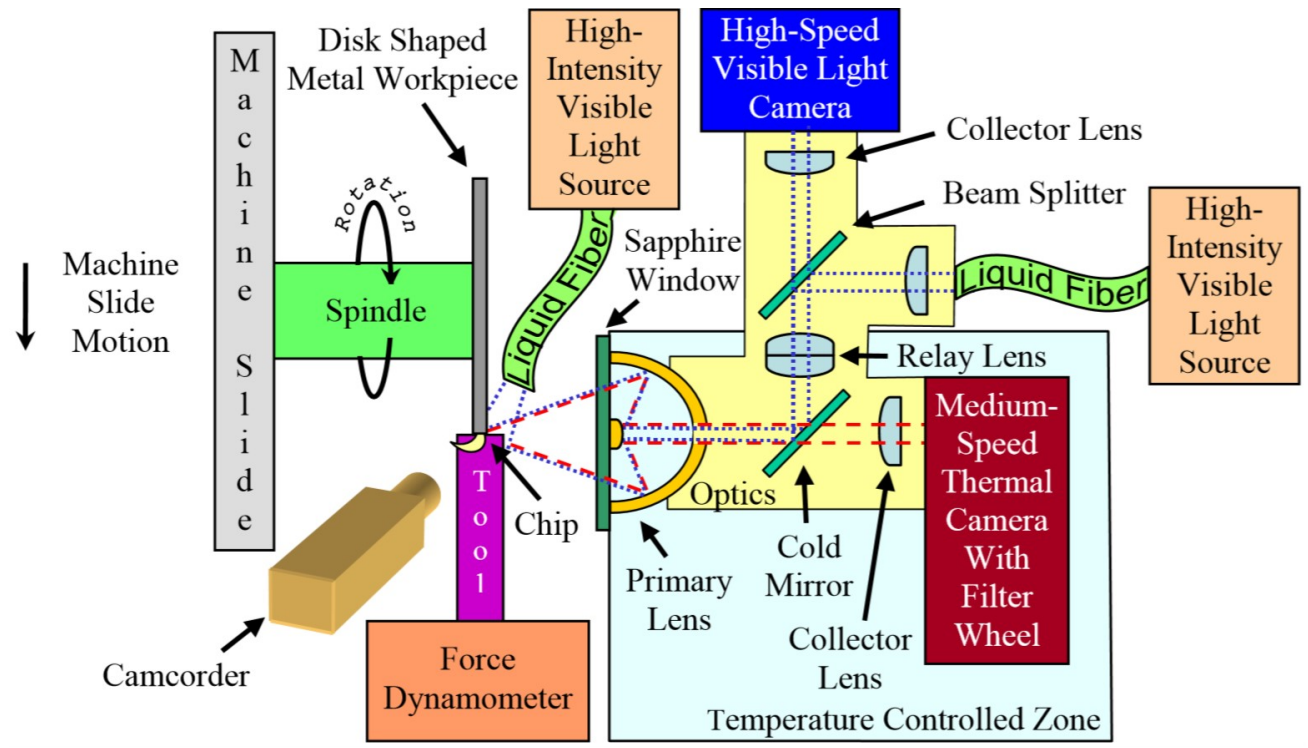

Figure 10. MADMACS dual-spectrum optical system developed by [68].

Table 3. Mechanical and optical parameters that can be used with the MADMACS optical system that was developed by [68].

\begin{tabular}{ccccc}
\hline Channel & $\begin{array}{c}V_{c} \\
(\mathbf{m} / \mathbf{m i n})\end{array}$ & $\begin{array}{c}\mathbf{R} \\
(\mathbf{p x})\end{array}$ & $\begin{array}{c}f_{\text {aq }} \\
(\mathbf{f p s})\end{array}$ & $\begin{array}{c}\boldsymbol{t}_{\boldsymbol{i}} \\
(\boldsymbol{\mu s})\end{array}$ \\
\hline Visible & $30-300$ & $256 \times 128$ & 300,000 & $1-33$ \\
Infrared & & $160 \times 120$ & 300 & $9-20$ \\
\hline
\end{tabular}

Based on the work of [68], In [49] proposed an optical system for coupled kinematic and thermal fields measurement (Figure 11). The device (called VISIR) was equiped with an X15 reflective objective, allowing for the transmission of radiation over a wide range of wavelengths (>95\% for $[600, \ldots, 20,000 \mathrm{~nm}])$. The high-speed camera Fastcam SA3 and the thermal camera FLIR SC7000 were coupled via two different channels. While using a silicon separator plate (thickness of $1 \mathrm{~mm}$ ), the radiation coming from the observed scene is separated in two: the visible waves were reflected with a reflectance equal to $40 \%$ while the infrared waves were transmitted with a transmittance higher than $65 \%$ for a wavelength range in [2000 nm, ..., 20,000 nm]. The use of a parabolic mirror in the infrared channel allows for the thermal waves to be reflected and focused on the infrared camera sensors. For the visible channel, it was equipped with a 50R/50T beam splitter and tube lens to 
focus the visible waves on the high-speed camera sensors. The 50R/50T beam splitter was also used for coaxial illumination. The light source was composed of $1040 \mathrm{~lm}$ power LEDs, providing a luminance of $10^{6}$ lux. Although the author obtained images with sufficient quality allowing for a proper application of the DIC technique, the light source proved to be limiting factor, since the integration time was limited to $20 \mu \mathrm{s}$.

Table 4 summarizes the mechanical and optical parameters used in the context of kinematic fields measurement.

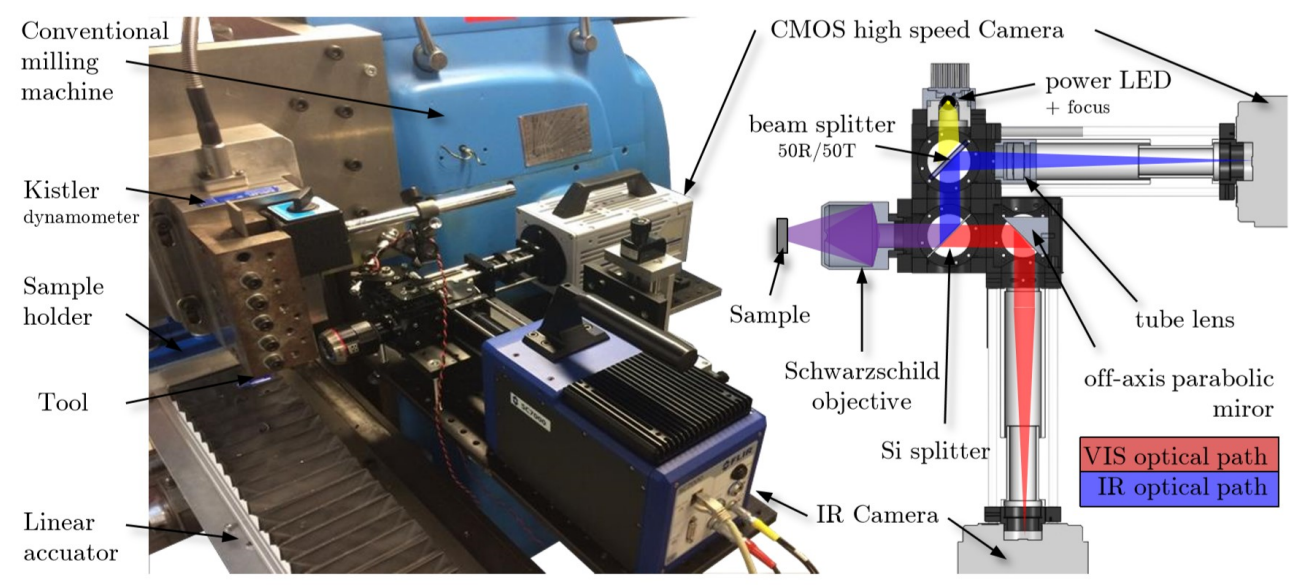

Figure 11. Visible and infrared imaging system (VISIR) developed by [49].

Although Hijazi [38] succeed in synchronizing four high-speed cameras to obtain eight visual images with a high frame rate (of the order of $1 \mathrm{MHz}$ ), this technique is shown to be complicated from a technical standpoint. In addition, this optical system can not be used for kinematic fields measurement during one segment chip formation because it does not allow to record a continuous film. Using a high-speed camera with a dual-frame mode is limited by the maximum repetition rate, which is considerably low (15 Hz in [24]). However, this dual-frame mode is highly recommended when studying the surface integrity. Baizeau [24] succeed in obtaining high resolved images (one before the cut and one after the cut), allowing for kinematic field measurements on the subsurface of the workpiece.

On the other hand, Harzallah [46,49] presented a coupled visible and infrared imaging system (VISIR). This optical system offered real-time insight on the material flow and recorded a continuous film about segment chip formations during machining. The highspeed camera used a standard mode. The images were obtained with sufficient quality, allowing for a proper application of the DIC technique for kinematic fields meausrement during one segment chip formation. The obtained results highlighted localized deformation bands when cutting the Ti-6Al-4V with a low cutting speed of $3 \mathrm{~m} / \mathrm{min}$. 
Table 4. Mechanical and optical parameters that were used in the context of kinematic fields measurement during machining.

\begin{tabular}{|c|c|c|c|c|c|c|c|c|c|}
\hline Reference & Material & $V_{c}(\mathrm{~m} / \mathrm{min})$ & $\mathrm{f}(\mathrm{mm})$ & Size $\left(\mathrm{mm}^{2}\right)$ & Magnification & Resolution (px) & $\begin{array}{l}\text { Pixel Size } \\
(\mu \mathrm{m} / \mathrm{px})\end{array}$ & $f_{a q}$ (fps) & $t_{i}(\mu \mathrm{s})$ \\
\hline [29] & Brass & $0.25 \times 10^{-3}$ & NS & NS & $X 25$ & NS & NS & NS & 2 \\
\hline [60] & Copper & 0.6 & 0.1 & NS & X3 & NS & 3.3 & 250 & NS \\
\hline [33] & 42CrMo4 & $150 / 300$ & $0.2 / 0.3$ & $1 \times 1$ & $\mathrm{X} 12$ & NS & NS & $22.5-25 \times 10^{3}$ & 1 \\
\hline [38] & AISI 1045 & 200 & 0.15 & $0.35 \times 0.25$ & $X 25$ & $1296 \times 925$ & 0.27 & $10^{6}$ & NS \\
\hline [39] & Al6061-T6 & 0.6 & 0.1 & $2.1 \times 2.1$ & $\mathrm{X} 3$ & $256 \times 256$ & 8.2 & 250 & NS \\
\hline [40] & $42 \mathrm{CrMo} 4$ & 30 & 0.1 & NS & X15 & $256 \times 128$ & NS & 30,000 & 33 \\
\hline [42] & Ti-Mg & 0.6 & 0.2 & $1.4 \times 1.4$ & NS & $1000 \times 1000$ & 1.4 & 2000 & NS \\
\hline [36] & AISI1018 & 1020 & 0.84 & $1.75 \times 1.75$ & $\mathrm{X} 10$ & $1024 \times 1024$ & 1.7 & NS & NS \\
\hline [43] & Ti-6Al-4V & 6 & 0.25 & $0.65 \times 0.6$ & $\mathrm{X} 10$ & $384 \times 352$ & 1.65 & 18,000 & 6.6 \\
\hline [44] & Brass & 0.06 & $0.05-0.15$ & $4.3 \times 2.4$ & $\mathrm{X} 5$ & $1296 \times 720$ & 3.3 & NS & NS \\
\hline [61] & Copper & $6 \times 10^{-4}$ & $0.1-0.25$ & $1 \times 1$ & NS & $1000 \times 1000$ & 1 & 50 & NS \\
\hline [53] & GS & 36 & 15 & $5 \times 5$ & $\mathrm{X7}$ & $1000 \times 1000$ & 5 & 7000 & NS \\
\hline [54] & Al7075-T6 & $0.35 / 0.5$ & $0.1 / 0.15$ & $1.68 \times 0.94$ & $\mathrm{X} 12$ & $1920 \times 1080$ & 0.875 & NS & NS \\
\hline \multirow[t]{2}{*}[24]{} & AW7020-T6 & 90 & 0.1 & $1.7 \times 1.4$ & $\mathrm{X} 10$ & NS & 0.66 & $\begin{array}{c}\max .1 / \\
\left(120 \times 10^{-9}\right)\end{array}$ & $10 /$ \\
\hline & & & & & & & & & $20 \times 10^{3}$ \\
\hline [55] & Al6061-T6 & 0.1 & $0.06 / 0.08 / 0.1$ & $1.75 \times 0.98$ & $\mathrm{X} 12$ & $1920 \times 1080$ & 0.916 & 1000 & NS \\
\hline \multirow[t]{2}{*}{ [46] } & Ti-6Al-4V & $3 / 15$ & 0.25 & $0.58 \times 0.58$ & X15 & $512 \times 512$ & 1.133 & 6000 & 50 \\
\hline & & & & $0.43 \times 0.39$ & & $384 \times 352$ & & 10,000 & \\
\hline [48] & ECAE Ti & 30 & 0.1 & $0.5 \times 0.5$ & $\mathrm{X} 12$ & $1024 \times 1024$ & 5 & 50,000 & NS \\
\hline
\end{tabular}




\section{Results/Discussion}

In the context of kinematic fields measurement during machining, Ref. [24] used the global appraoch with Correli-Q4 software to: (i) map the norm of the displacement vectors (Figure 12a) for an automatic measurement of the shear angle and (ii) map the displacement field in the subsurface of the workpiece (Figure 12b) in order to study the surface integrity.
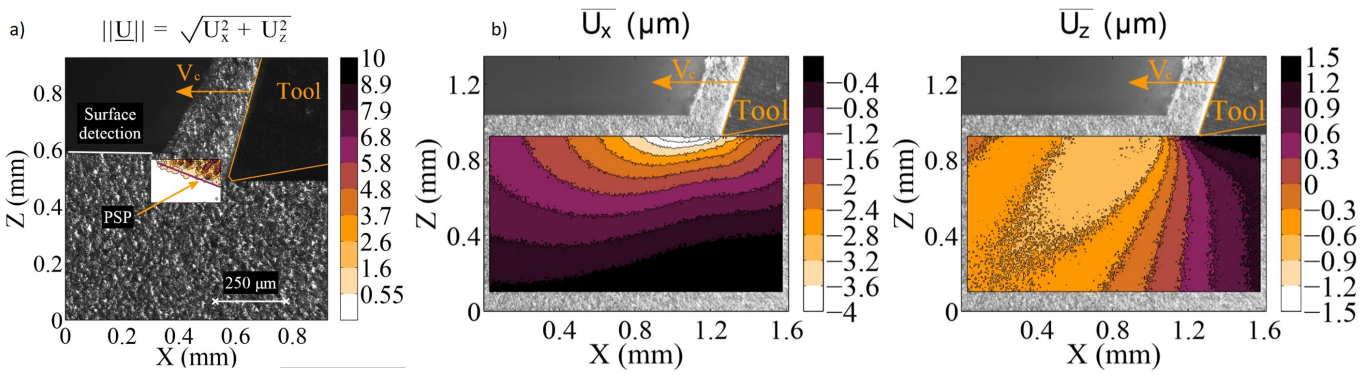

Figure 12. (a) Displacement field in the primary shear zone for automatic measurement of the shear angle and (b) displacement field in the subsurface of the workpiece during orthogonal cutting [24].

Most of the commercial digital image correlation software use the local approach, as described above. In the context of kinematic fields measurement during machining, some authors $[43,46,47,69]$ used the approach that was offered by the $7 \mathrm{~d}$ sotware. The DIC was applied on a sequence of images captured during one segment chip formation. Because of the fluctuation of light, a Zero-Normalized Cross-Correlation criterion (ZNCC) was used for the pattern matching procedure. This correlation criterion is insensitive to a scale in lighting, according to [51,70]. Bilinear (second-order [52,70]) shape functions were chosen. Because of a loss in image quality, an incremental correlation was employed. In order to allow for particle tracking, Pottier [43,69] developed a framework allowing the determination of the cumulative displacement field from the incremental displacement field returned by the DIC technique. Thus, the temporal evolution of the cumulative displacement and strain fields during one segment chip formation were determined. The orthogonal cutting test was made on Ti-6Al-4V workpiece with a cutting speed of $6 \mathrm{~m} / \mathrm{min}$. It was shown that the material is subjected to a significant strain magnitude (up to 3) inside the ASB. This strain magnitude was found to be overestimated, since the framework keeps cumulating strains, even though the material undergoes segmentation [43], denoted by a material disjunction or crack propagation. In order to monitor the crack propagation within the ASB, three material points were selected and the strain rate evolution on these points was investigated (Figure 13a). Based on the strain rate evolution that is shown in Figure 13b, the author suggests that the segment chip formation can be described by three stages:
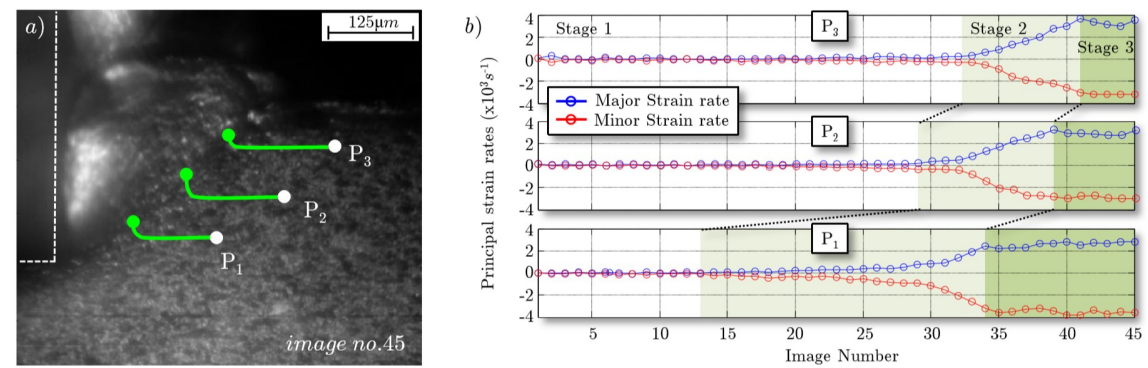

Figure 13. (a) Initial and final position of the three investigated points (P1, P2, and $\mathrm{P} 3$ ), (b) strain rate evolution for each point over the sequance of images [43].

- $\quad$ stage 1: strain concentration at the tool-tip vicinity.

- $\quad$ stage 2: rapid strain accumulation within the ASB from the tool tip to the free surface. The strain rate magnitude is up to $4 \times 10^{3} \mathrm{~s}^{-1}$ and leads to a material failure. 
- $\quad$ stage 3: the strain rate became stable and the segment chip is fully formed.

Based on Pottier's perspectives described in [43], Harzallah [49] used the same methogdology with a newly developed optical system. The cumulative displacement field was determined by post-processing the incremental displacement field returned by the DIC technique. Results of kinematic fields measurement when cutting Ti-6Al-4V at $15 \mathrm{~m} / \mathrm{min}$. are given in Figure 14. The author highlighted the crack propagation from the tool tip towards the free surface within the primary shear zone. The cumulative Henky strain field in the PSZ reaches 1.6 under a strain rate field of the order of $10^{3} \mathrm{~s}^{-1}$. The cumulative Henky stain was chosen in order to allow for comparison with numerical simulation giving eulerian outputs. Good correlation between the meausred kinematic fields during one segment chip formation and the numerical results using a new material behavior law $[13,46]$ was found.

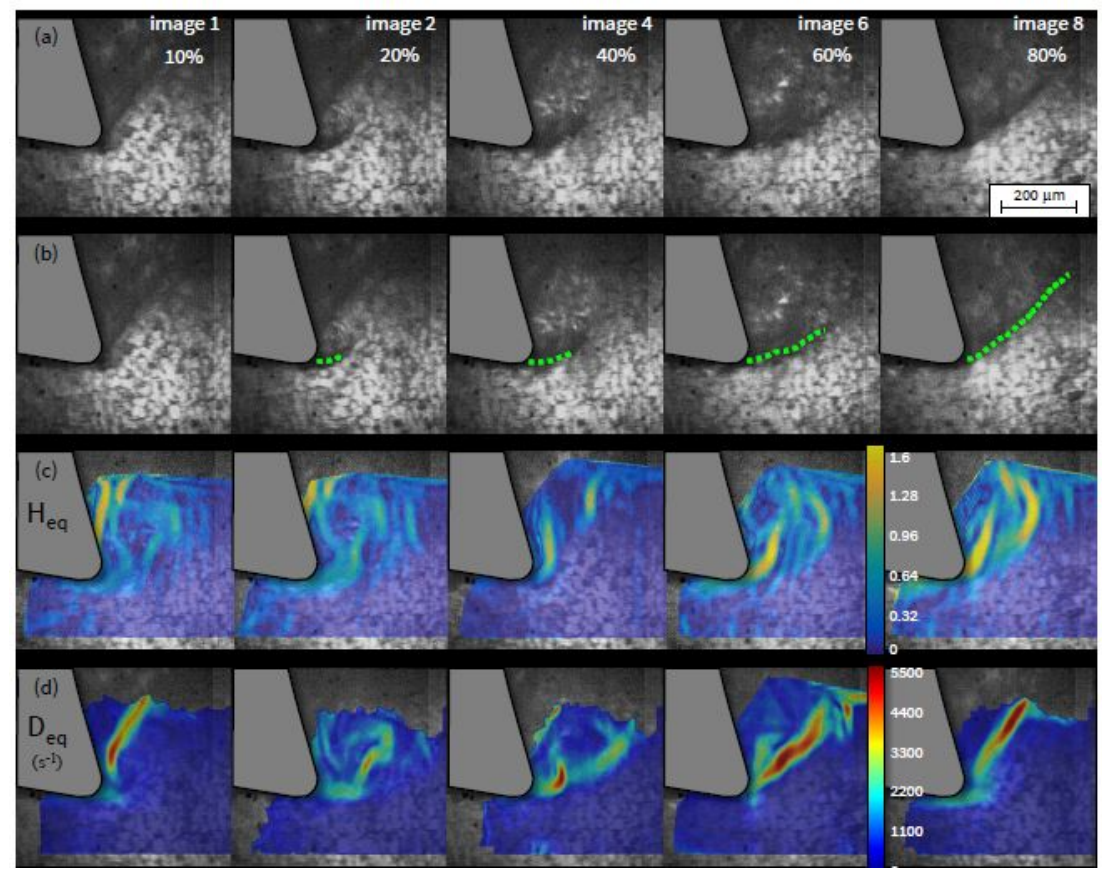

Figure 14. (a) Captured visual images at different instants during one segment chip formation; (b) crack propagation within the PSZ; and, (c) cumulative Henky strain field and (d) the equivalent strain rate field [49].

To conclude, Pottier and Harzallah $[43,46,49]$ have succeeding in developing a new optical system allowing for real-time insight on the material flow during one segment chip formation. Texture analysis was made and an acceptable standard deviation of the measured displacement was found, allowing for a proper application of the DIC technique. The authors were able to highlight localized deformation bands when cutting Ti-6Al-4V with low cutting speed.

Figure 15 summarizes the techniques used for kinematic fields measurement. For analytical technique and when using the grid distorsion analysis, it was found difficult to apply in the PSZ due to high distorsion. Moreover, the streamlines model shows to be limited to continuous chip formation. Numerous works demonstrated the efficiency of the DIC technique in kinematic fields measurements during orthogonal cutting tests $[24,25,38-41,43,46-$ 48,53-57]. In addition, It offers a high spatial resolution of the measured displacement field. Table 5 gives the magnitude of the measured plastic strain and strain rate within the PSZ with the corresponding cutting parameters. 
Table 5. Plastic strain and strain rate magnitude function of the cutting parameters.

\begin{tabular}{cccccc}
\hline Reference & Material & $\mathbf{V}_{\boldsymbol{c}}(\mathbf{m} / \mathbf{m i n})$ & $\mathbf{f}(\mathbf{m m})$ & $\boldsymbol{\varepsilon}$ & $\dot{\varepsilon}\left(\mathbf{s}^{\mathbf{- 1}}\right)$ \\
\hline$[54]$ & Al7075-T651 & 0.35 and 0.5 & 0.15 and 0.1 & $1-2$ & $10^{2}$ \\
{$[43]$} & Ti-6Al-4V & 6 & 0.25 & 3 & $10^{3}$ \\
{$[46]$} & Ti-6Al-4V & 3 and 15 & 0.25 & $1.2-1.7$ & $10^{3}$ \\
{$[48]$} & ECAE Ti & 30 & 0.1 & 1 & $10^{3}$ \\
{$[57]$} & NAB & 30 & 0.1 & $1.2-1.4$ & $10^{3}$ \\
& & 150 & & & $10^{4}$ \\
\hline
\end{tabular}

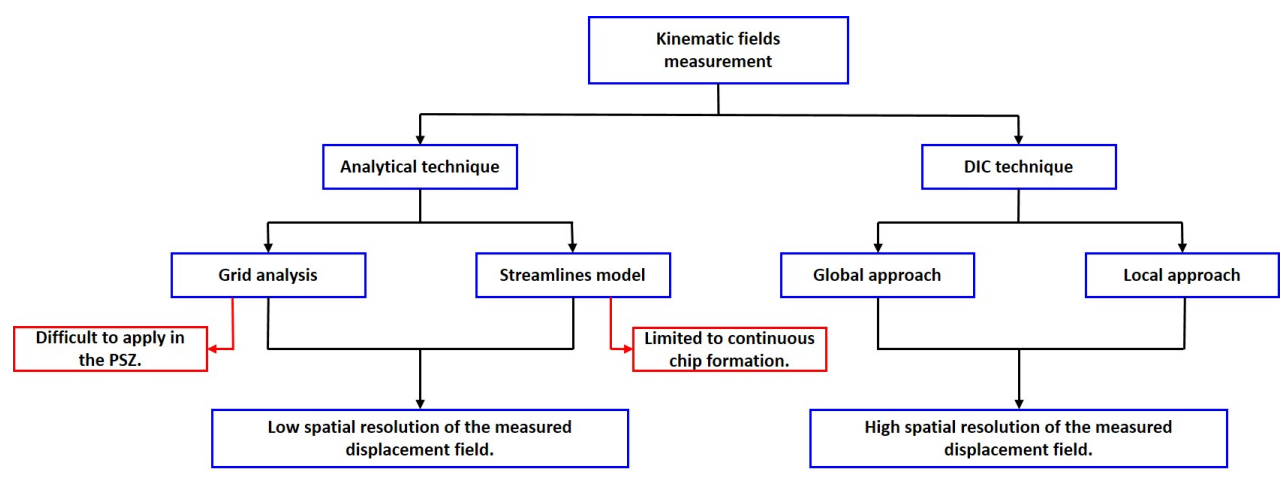

Figure 15. Kinematic fields measurement: analytical technique and the DIC technique.

- for Al7075-T651 and with low cutting speed, the plastic strain magnitude is ranging from 1 to 2 with a strain rate magnitude of $10^{2} \mathrm{~s}^{-1}$ [54];

- for titanium alloys $[43,46,48]$ and with a cutting speed ranging from 3 to $30 \mathrm{~m} / \mathrm{min}$., the plastic strain magnitude is ranging from 1 to 3 with a strain rate magnitude of $10^{3} \mathrm{~s}^{-1}$; and,

- for nickel based alloy and with a cutting speed of $30 \mathrm{~m} / \mathrm{min}$ (respectively $150 \mathrm{~m} / \mathrm{min}$.), the plastic strain magnitude is ranging from 1.2 to 1.4 with a strain rate magnitude of $10^{3} \mathrm{~s}^{-1}$ (respectively $10^{4} \mathrm{~s}^{-1}$ ) [57].

\section{Conclusions}

This paper discusses techniques that are used for kinematic fields measurement during machining. in-situ visualization of the material flow within a sub-mellimetric zone, namely the cutting zone, remains a non-trivial task. Nevertheless, the great interest in understanding local pheneomena has led many researchers to develop experiments allowing for collecting data regarding the chip formation. The following conclusions are made:

1. in-situ investigation of the material flow during machining requires surface preparation of the workpiece. Various techniques of surface preparation were discussed and classified in term of created pattern size. It was found that the "polishing based" technique is the most suitable for kinematic fields measurement in orthogonal cutting. It offers an acceptable pattern size sufficient enough to identify high localized deformation band. The speckle pattern size is identified through texture analysis. Various texture analysis tools were discussed. The MIG aproach and rigid body motion approach prove to be the most reliable tools in evaluating the property of the DIC application.

2. With the development of high-speed cameras, significant progress on the kinematic fields measurement has been made. The basics of high-speed camera were discussed and yield a definition of a methodology that can be followed to determine the optimum optical parameters.

3. With the recent advances on the design of optical systems, real-time insight on the material flow during orthogonal cutting through surface observation of the PSZ was 
made possible. Captured images with sufficient quality can be obtained allowing for a proper application of the DIC technique.

4. Details on the used two approaches (global and local) with the DIC technique were presented. The choice of the appropriate correlation criterion is important. It was found that the ZNCC (Zero-Normalized Cross Correlation) and the ZNSSD (ZeroNormalized Sum of Squared Differences) correlation criteria are the most suitable, due to the fact that both criteria are insensitive to a scale in lighting. Because of the loss of image quality, the incremental correlation type is priviliged for the kinematic fields measurement during orthogonal cutting.

5. During orthogonal cutting, the material undergones translation, rotation, and shear. Thus, minimum first-order shape functions are required for the displacement fields interpolation.

Author Contributions: Conceptualization, H.Z.; methodology, H.Z.; validation, M.C., V.W., O.C. and G.D.; investigation, H.Z.; writing-original draft, H.Z.; review and editing, M.C. and V.W.; supervision, M.C., V.W., O.C. and G.D.; project administration, O.C. and G.D. All authors have read and agreed to the published version of the manuscript.

Funding: This project received funding from the European Unions Marie Sklodowska-Curie Actions (MSCA) Innovative Training Networks (ITN) H2020-MSCA-ITN-2017 under the grant agreement $\mathrm{N}^{\circ} 764979$.

Conflicts of Interest: The authors declare no conflict of interest.

\section{References}

1. Jaspers, S.P.F.C.; Dautzenberg, J.H. Material behaviour in metal cutting: Strains, strain rates and temperatures in chip formation. J. Mater. Process. Technol. 2002, 121, 123-135. [CrossRef]

2. Germain, G.; Morel, A.; Braham-Bouchnak, T. Identification of Material Constitutive Laws Representative of Machining Conditions for Two Titanium Alloys: Ti6Al4V and Ti555-3. J. Eng. Mater. Technol. 2013, 135, 031002. [CrossRef]

3. Liu, R.; Melkote, S.; Pucha, R.; Morehouse, J.; Man, X.; Marusich, T. An enhanced constitutive material model for machining of Ti-6Al-4V alloy. J. Mater. Process. Technol. 2013, 213, 2238-2246. [CrossRef]

4. Johnson, G.R.; Cook, W.H. A constitutive model and data for materials subjected to large strains, high strain rates, and high temperatures. Proc. Seventh Int. Symp. Ballist. 1983, 21, 541-547.

5. Calamaz, M.; Coupard, D.; Girot, F. Numerical simulation of titanium alloy dry machining with a strain softening constitutive law. Mach. Sci. Technol. 2010, 14, 244-257. [CrossRef]

6. Sima, M.; Ozel, T. Modified material constitutive models for serrated chip formation simulations and experimental validation in machining of titanium alloy Ti-6Al-4V. Int. J. Mach. Tools Manuf. 2010, 50, 943-960. [CrossRef]

7. List, G. Etude des méCanismes d'endommagement des Outils Carbure WC-Co par la caractéRisation de l'interface Outil Copeau: Application à l'usinage à sec de l'alliage d'aluminium Aéronautique AA2024 T351. Ph.D. Thesis, ENSAM de Bordeaux, Paris, France, 2010.

8. Bahi, S. Modélisation Hybride du Frottement Local à l'interface Outil-Copeau en Usinage des Alliages Métalliques. Ph.D. Thesis, ENSAM de Bordeaux, Paris, France, 2004.

9. Atlati, S; Haddag, B.; Zenasni, M. Thermomechanical modelling of the tool-workmaterial interface in machining and its implementation using the ABAQUS VUINTER subroutine. Int. J. Mech. Sci. 2014, 87, 102-117. [CrossRef]

10. Mabrouki, T.; Girardin, F.; Asad, M.; Rigal, J.F. Numerical and experimental study of dry cutting for an aeronautic aluminium alloy (A2024-T351). Int. J. Mach. Tools Manuf. 2008, 48, 1187-1197. [CrossRef]

11. Karpat, Y. Temperature dependent flow softening of titanium alloy Ti6Al4V: An investigation using finite element simulation of machining. J. Mater. Process. Technol. 2011, 211,737-749. [CrossRef]

12. Huang, Y.; Ji, J.; Lee, K.M. An improved material constitutive model considering temperature-dependent dynamic recrystallization for numerical analysis of Ti-6Al-4V alloy machining. Int. J. Adv. Manuf. Technol. 2018, 97, 3655-3670. [CrossRef]

13. Harzallah, M.; Pottier, T.; Senatore, J.; Mousseigne, M.; Germain, G.; Landon, Y. Numerical and experimental investigations of Ti-6Al-4V chip generation and thermo-mechanical couplings in orthogonal cutting. Int. J. Mech. Sci. 2017, 134, 189-202. [CrossRef]

14. Courbon, C. Vers une Modélisation Physique de la Coupe des Aciers Spéciaux: Intégration du Comportement Métallurgique et des Phénomènes Tribologiques et Thermiques aux Interfaces. Ph.D. Thesis, Ecole Centrale de Lyon, Lyon, France, 2011.

15. Rotella, G.; Dillon, O.W., Jr.; Umbrello, D.; Settineri, L.; Jawahir, I.S. Finite element modeling of microstructural changes in turning of AA7075-T651 Alloy. J. Manuf. Process. 2013, 15, 87-95. [CrossRef]

16. Jafarian, F.; Imaz Ciaran, M.; Umbrello, D.; Arrazola, P.J.; Filice, L.; Amirabadi, H. Finite element simulation of machining Inconel 718 alloy including microstructure changes. Int. J. Mech. Sci. 2014, 88, 110-121. [CrossRef] 
17. Wang, Q.; Liu, Z.; Wang, B.; Song, Q; Wan, Y. Evolutions of grain size and micro-hardness during chip formation and machined surface generation for Ti-6Al-4V in high-speed machining. Int. J. Adv. Manuf. Technol. 2015, 82, 1725-1736. [CrossRef]

18. Wagner, V.; Barelli, F.; Dessein, G.; Laheurte, R.; Darnis, P.; Cahuc, O.; Mousseigne, M. Comparison of the chip formations during turning of Ti64 beta and Ti64 alpha+beta. J. Eng. Manuf. 2019, 233, 494-504. [CrossRef]

19. Barelli, F. Développement d'une Méthodologie D'optimisation des Conditions d'usinage: Application au Fraisage de l'alliage de Titane TA6V. Ph.D. Thesis; Université de Toulouse, Toulouse, France, 2016.

20. Ramirez, C. Critères d'optimisation des Alliages de Titane pour Améliorer leur Usinabilité. Ph.D. Thesis, ENSAM de Cluny, Paris, France, 2017.

21. Battaglia, J.; Puigsegur, L.; Cahuc, O. Estimated temperature on a machined surface using an inverse approach. Exp. Heat Transf. 2006, 18, 13-32. [CrossRef]

22. Cahuc, O.; Darnis, P.; Laheurte, R. Mechanical and Thermal Experiments in Cutting Process for New Behaviour Law. Int. J. Form. Process. 2007, 10, 235-269. [CrossRef]

23. Haddag, B.; Atlati, S.; Zenasni, M. Analysis of the heat transfer at the tool-workpiece interface in machining: Determination of heat generation and heat transfer coefficients. Heat Mass Transf. 2015, 51, 1355-1370. [CrossRef]

24. Baizeau, T.; Campocasso, S.; Fromentin, G.; Besnard, R. Kinematic Field Measurements During Orthogonal Cutting Tests via DIC with Double-frame Camera and Pulsed Laser Lighting. Exp. Mech. 2008, 57, 581-591. [CrossRef]

25. Zhang, D.; Zhang, X.M.; Leopold, J.; Ding, H. Subsurface Deformation Generated by Orthogonal Cutting: Analytical Modeling and Experimental Verification. J. Manuf. Sci. Eng. 2017, 139, 094502. [CrossRef]

26. Bitans, K.; Brown, R.H. An investigation of the deformation in orthogonal cutting. Int. J. Mach. Tool Des. Res. 1965, 5, 155-165. [CrossRef]

27. Brown, R.H. A double shear-pin quick-stop device for very rapid disengagement of a cutting tool. Int. J. Mach. Tool Des. Res. 1976, 16, 115-121. [CrossRef]

28. Vorm, T. Development of a quick-stop device and an analysis of the "frozen-chip" technique. Int. J. Mach. Tool Des. Res. 1976, 16, 241-250. [CrossRef]

29. Childs, T.H.C. A new visio-plasticity technique and a study of curly chip formation. Int. J. Mech. Sci. 1971, 13, 373-387. [CrossRef]

30. Shaik, J.; Ramakrishnan, K. Subsurface plastic deformation in machining annealed 18\% ni maraging steel. J. Wear 1982, 81, 263-273.

31. Shaik, J.; Ramakrishnan, K. Subsurface plastic deformation in machining annealed red brass. J. Wear 1982, 82, 67-79.

32. Ghadbeigi, H.; Bradbury, S.R; Pinna, C.; Yates, J.R. Determination of micro-scale plastic strain caused by orthogonal cutting. Int. J. Mach. Tools Manuf. 2008, 48, 228-235. [CrossRef]

33. Pujana, J.; Arrazola, P.J.; Villar, J.A. In-process high-speed photography applied to orthogonal turning. J. Mater. Process. Technol. 2008, 202, 475-485. [CrossRef]

34. Hasani, A.; Lapovok, R.; Toth, L.S.; Molinari, A. Deformation field variations in equal channel angular extrusion due to back pressure. Scr. Mater. 2008, 58, 771-774. [CrossRef]

35. Bi, X., List, G.; Liu, Y.X. Calculation of Material Flow in Orthogonal Cutting by Using Streamline Model. Key Eng. Mater. 2009, 407, 490-493. [CrossRef]

36. List, G.; Sutter, G.; Bi, X.F.; Molinari, A.; Bouthiche, A. Strain, strain rate and velocity fields determination at very high cutting speed. J. Mater. Process. Technol. 2013, 213, 693-699. [CrossRef]

37. Komanduri, R.; Brown, R.H. On the Mechanics of Chip Segmentation In Machining. J. Eng. Ind. 1981, 103, 33-51. [CrossRef]

38. Hijazi, A.; Madhavan, V. A novel ultra-high speed camera for digital image processing applications. Meas. Sci. Technol. 2008, 19. [CrossRef]

39. Gnanamanickam E.P.; Lee, S.; Sullivan, J.P.; Chandrasekar, S. Direct measurement of large-strain deformation fields by particle tracking. Meas. Sci. Technol. 2009, 20, 095710. [CrossRef]

40. Arriola, I.; Whitenton, E.; Heigel, J.; Arrazola, P.J. Relationship between machinability index and in-process parameters during orthogonal cutting of steels. CIRP Ann. 2011, 60, 93-96. [CrossRef]

41. Calamaz, M.; Coupard, D.; Girot, F. Strain Field Measurement in Orthogonal Machining of a Titanium Alloy. Adv. Mater. Res. 2012, 498, 237-242. [CrossRef]

42. Guo, Y.; Efe, M.; Moscoso, W.; Sagapuram, D.; Trumble, K.P.; Chandrasekar, S. Deformation field in large-strain extrusion machining and implications for deformation processing. Scr. Mater. 2012, 66, 235-238. [CrossRef]

43. Pottier, T.; Germain, G.; Calamaz, M.; Morel, A.; Coupard, D. Sub-Millimeter Measurement of Finite Strains at Cutting Tool Tip Vicinity. Exp. Mech. 2015, 54, 1031-1042. [CrossRef]

44. Guo, Y.; Dale Compton, W.; Chandrasekar, S. In situ analysis of flow dynamics and deformation fields in cutting and sliding of metals. Proc. R. Soc. Math. Phys. Eng. Sci. 2015, 471, 20150194. [CrossRef]

45. Baizeau, T. Développements Expérimentaux et Numériques pour la Caractérisation des Champs Cinématiques de la Coupe de l'acier 100 CrMo 7 Durci Pour la Prédiction de l'intégrité de Surface. Ph.D. Thesis, ENSAM de Cluny, Paris, France, 2016.

46. Harzallah, M. Caractérisation in-situ et modélisation des mécanismes et couplages thermomécaniques en usinage: Application à l'alliage de titane Ti-6Al-4V. Ph.D. Thesis, Université de Toulouse, Toulouse, France, 2018.

47. Zeramdini, B. Apport des Méthodes de Remaillage Pour la Simulation de Champs Localisés. Validation en Usinage par Corrélation D'images. Ph.D. Thesis, ENSAM Angers, Paris, France, 2018. 
48. Davis, B.; Dabrow, D.; Ifju, P.; Xiao, G.; Liang, S.Y.; Huang, Y. Study of the Shear Strain and Shear Strain Rate Progression During Titanium Machining. J. Manuf. Sci. Eng. 2018, 140, 051007. [CrossRef]

49. Harzallah, M.; Pottier, T.; Gilblas, R.; Landon, Y.; Mousseigne, M.; Senatore, J. A coupled in-situ measurement of temperature and kinematic fields in Ti-6Al-4V serrated chip formation at micro-scale. Int. J. Mach. Tools Manuf. 2018, 130-131, 20-35. [CrossRef]

50. Wang, B.; Pan, B.; Lubineau, G. Some practical considerations in finite element-based digital image correlation. Opt. Lasers Eng. 2015, 73, 22-32. [CrossRef]

51. Pan, B.; Qian, K.; Xie, H.; Asundi, A. Two-dimensional digital image correlation for in-plane displacement and strain measurement: a review. Meas. Sci. Technol. 2009, 20, 062001. [CrossRef]

52. Bornert, M.; Bremand, F.; Doumalin, P.; Dupré, J.C.; Fazzini, M.; Hild, F.; Mistou, S.; Molimard, J.; Orteu, J.J.; Robert, L.; et al Assessment of Digital Image Correlation Measurement Errors: Methodology and Results. Exp. Mech. 2009, 49, 353-370. [CrossRef]

53. Moulart, R.; Fouilland, L.; El Mansori, M. Développement d'Une Méthode de Mesure de Champs cinéMatiques Pour éTudier la Coupe à Chaud; HAL-01178165; Congrès Français de Mécanique (CFM): Lyon, France, 2015.

54. Zhang, D.; Zhang, X.M.; Xu, W.J.; Ding, H. Stress Field Analysis in Orthogonal Cutting Process Using Digital Image Correlation Technique. J. Manuf. Sci. Eng. 2016, 139, 031001. [CrossRef]

55. Zhang, D.; Zhang, X.M.; Ding, H. Hybrid Digital Image Correlation-Finite Element Modeling Approach for Modeling of Orthogonal Cutting Process. J. Manuf. Sci. Eng. 2018, 140, 041018. [CrossRef]

56. Zhang, D. Zhang, X.M.; Ding, H. Inverse identification of material plastic constitutive parameters based on the DIC determined workpiece deformation fields in orthogonal cutting. Procedia CIRP 2018, 71, 134-139. [CrossRef]

57. Zhang, X.M.; Zhang, K.; Zhang, D.; Outeiro, J.; Ding, H. New In Situ Imaging-Based Methodology to Identify the Material Constitutive Model Coefficients in Metal Cutting Process. J. Manuf. Sci. Eng. 2019, 141, 101007-1-101007-11. [CrossRef]

58. Blanchet, F. Etude de la Coupe en Perçage par le Biais d'essais élémentaires en Coupe Orthogonale: Application aux Composites Carbone-époxy. Ph.D. Thesis, Université de Toulouse, Toulouse, France, 2015.

59. Sutter, G. Chip geometries during high-speed machining for orthogonal cutting conditions. Int. J. Mach. Tools Manuf. 2005, 45, 719-726. [CrossRef]

60. Lee, S.; Hwang, J.; Shankar, M.R.; Chandrasekar, S.; Dale Compton, W. Large strain deformation field in machining. Metall. Mater. Trans. Phys. Metall. Mater. Sci. 2006, 37, 1633-1643. [CrossRef]

61. Cai, S.L.; Ye, G.G.; Jiang, M.Q; Wang, H.Y.; Dai, L.H. Characterization of the deformation field in large-strain extrusion machining. J. Mater. Process. Technol. 2015, 216, 48-58. [CrossRef]

62. Besnard, G.; Hild, F.; Roux, S. "Finite-Element" Displacement Fields Analysis from Digital Images: Application to Portevin-Le Châtelier Bands. Exp. Mech. 2006, 46, 789-803. [CrossRef]

63. Triconnet, K.; Derrien, K.; Hild, F.; Baptiste, D. Parameter Choice for Optimized Digital Image Correlation. Opt. Lasers Eng. 2009, 47, 728-737. [CrossRef]

64. Hild, F.; Roux, S. A Software for "Finite-Element" Displacement Field Measurements by Digital Image Correlation; Internal Report NO 239; ENS de Cachan: Gif-sur-Yvette, France, 2008.

65. Pan, B.; Lu, Z.; Xie, H. Mean intensity gradient: An effective global parameter for quality assessment of the speckle patterns used in digital image correlation. Opt. Lasers Eng. 2010, 48, 469-477. [CrossRef]

66. Xing, H.Z.; Zhang, Q.B.; Braithwaite, C.H.; Pan, B.; Zhao, J. High-Speed Photography and Digital Optical Measurement Techniques for Geomaterials: Fundamentals and Applications. Rock Mech. Rock Eng. 2017, 50, 1-49.

67. Fuller, P.W.W. An introduction to high speed photography and photonics. Exp. Mech. 2009, 57, 293-302. [CrossRef]

68. Whitenton, E.P. High-speed dual-spectrum imaging for the measurement of metal cutting temperatures. In NIST Interagency/Internal Report (NISTIR)-7650; NIST: Gaithersburg, MD, USA, 2010.

69. Pottier, T. Projet MEDEX: Rapport Technique; Internal Report; ENSAM Angers: Paris, France, 2013.

70. Khoo, S.W.; Karuppanan, S.; Tan, C.S. A Review of Surface Deformation and Strain Measurement Using Two-Dimensional Digital Image Correlation. Metrol. Meas. Syst. 2016, 23, 461-480. [CrossRef] 